\title{
Novel nanomaterial-based antibacterial photodynamic therapies to combat oral bacterial biofilms and infectious diseases
}

This article was published in the following Dove Press journal: International Journal of Nanomedicine

\author{
Manlin $Q i^{1,2}$ \\ Minghan $\mathrm{Chi}^{1,2}$ \\ Xiaolin Sun ${ }^{1,2}$ \\ Xianju Xie ${ }^{3,4}$ \\ Michael D Weir ${ }^{4}$ \\ Thomas W Oates ${ }^{4}$ \\ Yanmin Zhou ${ }^{1,2}$ \\ Lin Wang ${ }^{1,2,4}$ \\ Yuxing $\mathrm{Bai}^{3}$ \\ Hockin HK $\mathrm{Xu}^{4-6}$ \\ 'Department of Oral Implantology, \\ School and Hospital of Stomatology, Jilin \\ University, Changchun I3002I, People's \\ Republic of China; ${ }^{2}$ jilin Provincial Key \\ Laboratory of Sciences and Technology \\ for Stomatology Nanoengineering, \\ Changchun 13002I, People's Republic of \\ China; ${ }^{3}$ Department of Orthodontics, \\ School of Stomatology, Capital Medical \\ University, Beijing, People's Republic of \\ China; ${ }^{4}$ Department of Advanced Oral \\ Sciences and Therapeutics, University of \\ Maryland School of Dentistry, Baltimore, \\ MD 2I20I, USA; ${ }^{5}$ Center for Stem Cell \\ Biology and Regenerative Medicine, \\ University of Maryland School of \\ Medicine, Baltimore, MD 2I20I, USA; \\ ${ }^{6}$ University of Maryland Marlene and \\ Stewart Greenebaum Cancer Center, \\ University of Maryland School of \\ Medicine, Baltimore, MD 2/20I, USA
}

Correspondence: Lin Wang; Yanmin Zhou Department of Oral Implantology, School and Hospital of Stomatology, Jilin

University, Changchun I3002I, People's

Republic of China

Tel +8643I88796025

Email wanglin 1982@jlu.edu.cn;

zhouym@jlu.edu.cn

\begin{abstract}
Oral diseases such as tooth caries, periodontal diseases, endodontic infections, etc., are prevalent worldwide. The heavy burden of oral infectious diseases and their consequences on the patients' quality of life indicates a strong need for developing effective therapies. Advanced understandings of such oral diseases, e.g., inflammatory periodontal lesions, have raised the demand for antibacterial therapeutic strategies, because these diseases are caused by viruses and bacteria. The application of antimicrobial photodynamic therapy (aPDT) on oral infectious diseases has attracted tremendous interest in the past decade. However, aPDT had a minimal effect on the viability of organized biofilms due to the hydrophobic nature of the majority of the photosensitizers (PSs). Therefore, novel nanotechnologies were rapidly developed to target the delivery of hydrophobic PSs into microorganisms for the antimicrobial performance improvement of aPDT. This review focuses on the state-of-the-art of nanomaterials applications in aPDT against oral infectious diseases. The first part of this article focuses on the cutting-edge research on the synthesis, toxicity, and therapeutic effects of various forms of nanomaterials serving as PS carriers for aPDT applications. The second part discusses nanomaterials applications for aPDT in treatments of oral diseases. These novel bioactive nanomaterials have demonstrated great potential to serve as carriers for PSs to substantially enhance the PDT therapeutic effects. Furthermore, the novel aPDT applications not only have exciting therapeutic potential to inhibit bacterial plaque-initiated oral diseases, but also have a wide applicability to other biomedical and tissue engineering applications.
\end{abstract}

Keywords: photodynamic therapy, nanomaterials, antibacterial, anti-inflammatory, upconversion nanoparticles, oral diseases

\section{Introduction}

The WHO recently published a global review of oral health which emphasized that, despite great improvements in the oral health of populations in several countries, serious global problems still persisted. ${ }^{1}$ The human oral cavity harvests a diverse ecosystem including over 700 species of microorganisms, including bacteria, archaea, fungi, and viruses. Increasing evidence indicated that the microbiota contributes to infectious oral diseases including caries, periodontal diseases, endodontic infections, etc. ${ }^{2}$ Dental caries and periodontal diseases are the most prevalent bacteria-infectious oral diseases in humans worldwide. Severe periodontal diseases (periodontitis) are the leading cause of multiple tooth loss and edentulism in adults. Dental caries is the most common chronic disease of childhood. The data from the 
Global Burden of Disease Study in 2010 showed that the global burden of periodontal diseases, oral cancer, and caries increased markedly, by an average of $45.6 \%$ from 1990 to $2010 .^{3}$ For example, pulpitis was caused by bacteria and their products entering the pulp through a deep caries lesion or a leaked filling. ${ }^{4}$ Moreover, in apical periodontitis, bacteria could invade and colonize the entire root canal system. ${ }^{4}$ In addition, with the infective microorganisms residing in the main canal, the bacteria could penetrate from the main root canal into dentinal tubules, lateral canals, and other canal irregularities, leading to secondary endodontic infections. ${ }^{4}$ Indeed, studies showed that dentin invasion occurred in $50-80 \%$ of the teeth with apical periodontitis. ${ }^{5,6}$

Antibiotics is usually applied in the treatment of such oral infectious diseases. However, it was shown that the minimal concentration of antibiotic for the eradication of bacterial biofilm was difficult to reach in vivo. $^{7}$ Furthermore, there was an increasing concern on the abuse of antibiotics due to bacterial drug-resistance. Recently, antimicrobial photodynamic therapy (aPDT) was investigated as a promising antibacterial therapeutic modality to eliminate the aforementioned shortcomings.

Photodynamic therapy (PDT) was discovered over 100 years ago by observing the killing of microorganisms when harmless dyes and visible light were combined in vitro. ${ }^{8}$ Since then, it was primarily developed as a treatment for cancer. Unlike traditional therapies (surgery, chemotherapy, and radiotherapy), PDT did not have severe side effects and could often be repeated. ${ }^{9}$ In recent years, the interest in the antimicrobial effects of PDT was revived. PDT was proposed as a therapy for a large variety of localized infections, ${ }^{10}$ and it was described as antimicrobial or antibacterial PDT, or photodynamic inactivation (PDI). aPDT employed appropriate excitation light in combination with photosensitizers (PSs) and oxygen, and allowed the non-specific attack against microorganisms by generating cytotoxic ROS, especially singlet oxygen $\left({ }^{1} \mathrm{O}_{2}\right) .{ }^{11}$ Singlet PS was extremely unstable and could instantaneously release the energy, returning to the triplet state. The released energy was absorbed by the tissue oxygen to form ROS, which had a strong oxidation and high reactivity, thus causing rapid lipid oxidation of the bacteria. This led to the destruction of the vulnerable membrane lipids and eventually the bacterial death. ${ }^{11}$

Several meritorious reviews on aPDT applications in dentistry had described the antimicrobial effects against oral infectious diseases, ${ }^{11-17}$ which were not repeated in the present article. The majority disadvantage of PSs was hydrophobic and poorly soluble in water. Therefore, a promising approach to enhancing the performance of PSs was to encapsulate them in nanostructured materials. The application of these nanocarriers would improve the drug availability for parenteral administration, by increasing the nanoparticle (NP) uptake for greater therapeutic efficacy. ${ }^{18}$ Therefore, the present article reviewed new developments in nanomaterial-based aPDT and the applications in dentistry, focusing on the bioactive and therapeutic effects against several key oral and dental infectious diseases.

\section{Nanomaterials in aPDT}

The aPDT researches attracted tremendous attention recently as an alternative approach to combating the drug-resistant microorganisms. It combined non-toxic PSs and harmless light of suitable wavelengths to produce antimicrobial effects by generating ROS, which eventually caused the cell death. Nevertheless, the drawbacks of PSs, including poor water-solubility, uncontrollable drugrelease profile, poor target selectivity, and low extinction coefficient, had hindered the clinical applications. ${ }^{19}$ In addition, photo-bleaching could cause unintended sideeffects and damage the healthy tissues. To overcome these limitations, novel precise designs of nanomaterials were developed to act as vehicles and loaded or embedded with PSs, or to act as PSs themselves. They possessed important properties ${ }^{19-23}$ : 1) controlled PSs releasing ability, 2) improved water-solubility, 3) preventing aggregation even at high concentrations, 4) good binding, easily uptaken by bacterial cells and generate larger yield of ROS, 5) selective antimicrobial activity at the local-targeted sites, 6) increased bacterial cell wall penetrability, and 7) broadening the photo-therapeutic window to optimize tissue-penetration depth.

\section{The use of nanoparticles to serve as photosensitizers \\ Fullerenes}

Fullerenes $\left(C_{n}, n=60,70,72,76,84\right.$, or 100$)$ were members of the closed-cage carbon molecules family which were entirely composed of $\mathrm{sp}^{2}$ hybridized carbon atoms, with pentagons and hexagons arranged in a soccer ball structure. ${ }^{20}$ Because of their extended $\pi$-conjugation, fullerene molecules had a long triplet-excited state lifetime, a high triplet yield and could produce ROS after illumination, indicating they could act as PSs in aPDT. ${ }^{24,25}$ In 
addition, fullerenes possessed several other advantages over traditional PSs, including: ${ }^{20,25}$ 1) High photostability (resistance to photobleaching), 2) versatile functionalization, 3) ability to carry out both type 1 and type 2 pathways and photochemistry, 4) enhancement of the overall ROS quantum yield, 5) possibility of oxygen-independent photo-killing by electron transfer, 6) potentiated antimicrobial activity by inorganic salts, and 7) formation of selfassembled NPs.

It was reported that fullerene and its derivatives displayed broad-spectrum antimicrobial photodynamic activities against both bacteria and fungi. ${ }^{26}$ The possible mechanism was the disturbance of the bacterial cell structure and metabolism by generating ${ }^{1} \mathrm{O}_{2}$, superoxide anions $\left(\mathrm{O}_{2}{ }^{-}\right)$, and free radicals ( $\mathrm{OH})$. Fullerenes with cationic-functionalized groups can potentiate the aPDT activity against microorganisms. ${ }^{27,28}$ Recently, a novel amine group-modified fullerene derivative $\mathrm{C}_{70}$-(ethylenediamine) $)_{8}$ showed a strong killing activity against superbacteria, and the ability to mitigate bacterial infection and accelerate wound healing. ${ }^{29}$ The addition of KI could further potentiate the aPDT effect of the photoactivated fullerenes on Gram-negative bacteria, Gram-positive bacteria, and fungus. ${ }^{30,31}$ In addition, several fullerene composites showed excellent photocatalytic inactivation activity. ${ }^{32,33}$ The irradiated Tetrakis[3-( $N$-ethylcarbazoyl)]porphyrin- $\mathrm{C}_{60}$ (TCP-C $\mathrm{C}_{60}$ ) film showed a 4 log decrease in Staphylococcus aureus (S. aureus) and Escherichia coli (E. coli) with 30 and 60 min irradiations. The irradiated $\mathrm{C}_{60} / \mathrm{C}_{3} \mathrm{~N}_{4}$ and $\mathrm{C}_{70} / \mathrm{C}_{3} \mathrm{~N}_{4}$ hybrid inactivated $86 \%$ and $100 \%$ of $E$. coli $\mathrm{O} 157: \mathrm{H} 7$ cells, respectively. ${ }^{33}$

However, the disadvantages of fullerenes application in aPDT include: 1) highly hydrophobic and easy to accumulate, 2) ultraviolet-visible absorption spectrum, and 3) antioxidants. ${ }^{25}$ Although these drawbacks could potentially become an obstacle for the application of fullerenes, many approaches could solve these problems. Surface modification (such as anionic or cationic functional groups) and supramolecular approaches (such as PEGylation and encapsulation) could be used to improve the aqueous solubility. ${ }^{34}$ Light-harvesting antennae ${ }^{35}$ and dual near-infrared (NIR) two-photon excitation ${ }^{36}$ can enhance the depth of light penetration. Paradoxically, fullerenes can be strong oxidizing agents or anti-oxidant ${ }^{37}$ with or without illumination.

\section{Graphene and carbon nanotubes}

Graphene and its derivatives were widely investigated due to their excellent conductivity, biocompatibility, non-toxicity, and photothermal activity. ${ }^{38}$ Recently, much attention was transferred to target microbial pathogens, which was becoming increasingly resistant to conventional therapy. ${ }^{39-42}$ Graphene oxide (GO) had unique properties such as a large surface area decorated with different functional groups, intrinsic high NIR absorbance and well-dispersed stability in aqueous solution, and was an ideal nanoplatform for PS delivery. Current advancement for PS delivery appeared to concentrate on multifunctional nanostructures for multimodel therapies. ${ }^{43}$ Tian et al loaded $\mathrm{Ce} 6$ onto polyethylene glycol (PEG) functionalized GO via $\pi-\pi$ stacking, and the GO-based PDT delivery had significantly increased intracellular Ce6 shuttling, thus enhancing the cancer cell killing efficacy upon light irradiation. ${ }^{44}$ Moreover, when combining photothermal therapy (PTT) with mild local heating using $808 \mathrm{~nm}$ laser, the cellular uptake of GO-PEG-Ce6 was increased by 2 folds. Therefore, GO-based nanomaterials showed the potential for targeted PTT and PDT. ${ }^{44}$ Similar synergistic bacteria-killings through physical action and PDT were also achieved by using $\mathrm{GO} / \mathrm{Ag} / \mathrm{Collagen}$ hybrids. ${ }^{40}$

Carbon nanotubes (CNTs) were another type of carbon-based scaffolds for encapsulating antimicrobial agents. CNTs were allotropes of carbon made by folding a sheet of graphene into a cylindrical nanostructure, with a high aspect ratio (length to diameter) and a large surface area. ${ }^{19,20,45}$ There were two types of CNTs including single-walled carbon nanotubes (SWNTs), and multi-walled carbon nanotubes (MWNTs). CNTs had excellent capabilities to develop ultrathin films with high surface area for immobilization of PSs, accompanied by their own abilities to yield ROS upon illumination. Therefore, extensive efforts were made to improve the antimicrobial ability of CNTs. ${ }^{45-49}$ Banerjee et al fabricated MWNT conjugated with protoporphyrin IX, and investigated aPDT efficacy against $S$. aureus via irradiation with visible light. The colonies of $S$. aureus was reduced by approximately 15$20 \%$, comparing to the area that was covered by the films (control) after $1 \mathrm{~h}$ light exposure. ${ }^{46}$ Since the lifetime and diffusion distance of ${ }^{1} \mathrm{O}_{2}$ was limited, a controllable singlet oxygen generation (SOG) with a high selectivity would be more efficient for aPDT. Zhu et al engineered a molecular complex of Ce6, $\alpha$-thrombin (Tmb) aptamer, and SWNTs to regulate the SOG. ${ }^{50}$ As shown in Figure 1, no significant difference of fluorescence was shown between buffer solution and aptamer-SWNTs. However, when 2.0 $\mu \mathrm{M}$ Tmb was added, the SOG fluorescence of aptamerSWNTs exhibited a 13-fold enhancement. Hence, the DNA interaction with SWNTs can be disturbed by the 

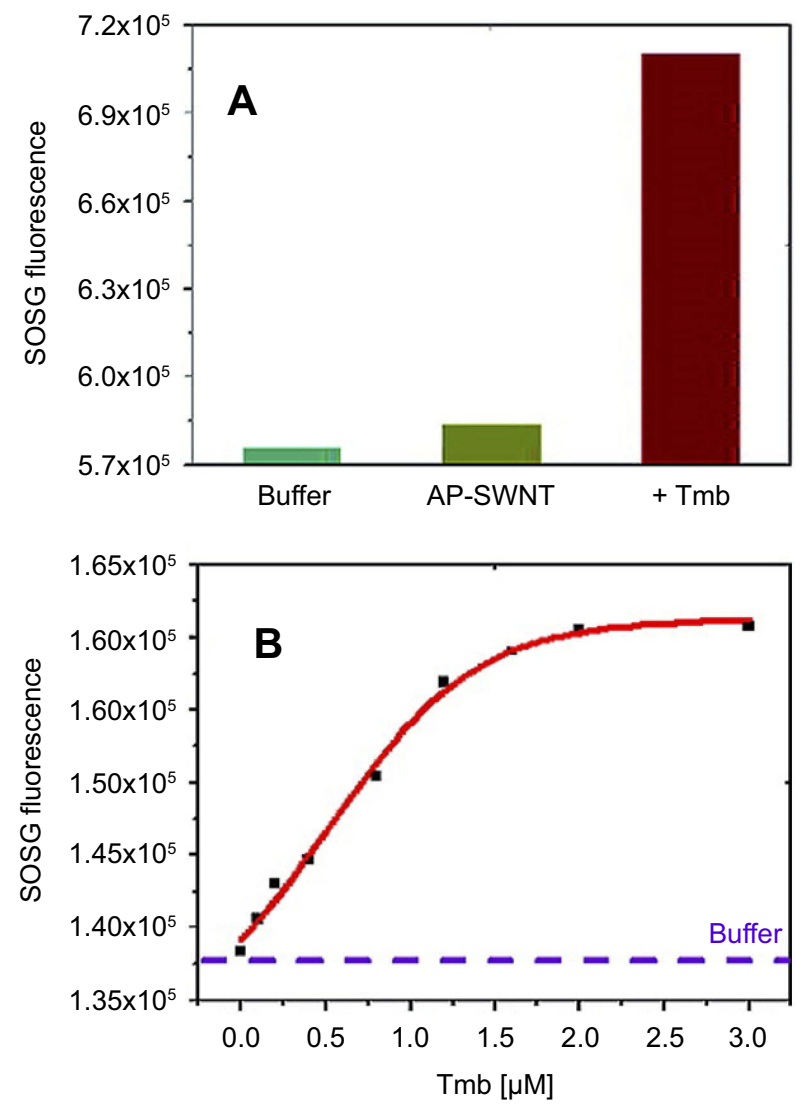

Figure I SOG regulation by aptamer-binding protein.

Notes: (A) SOSG signal readout after 10.5 mins of irradiation with excitation at $404 \mathrm{~nm}$. SWNTs showed great quenching for SOG. After introduction of $2.0 \mu \mathrm{M}$ thrombin, SOG was increased. (B) SOSG signal plotted as a function of Tmb concentration. The purple line indicates the buffer's SOSG signal. Reprinted with permission from Zhu Z, Tang Z, Phillips JA, Yang R, Wang H, Tan W. Regulation of singlet oxygen generation using single-walled carbon nanotubes. J Am Chem Soc. 2008; 130(33): 10856-10857. ${ }^{50}$ Copyright (2008) American Chemistry Society.

Abbreviations: SOG, singlet oxygen generation; SOSG, singlet oxygen sensor green; SWNTs, single-walled carbon nanotubes; Tmb, thrombin.

binding between the aptamer and the target molecule. This can cause the DNA to fall from the SWNT surface, thus promoting a restoration of SOG for PDT applications. ${ }^{50}$

\section{Metal oxides nanoparticles}

$\mathrm{ZnO}$ and $\mathrm{TiO}_{2}$ were semi-conducting materials with unique optical, biocompatible, and biodegradable properties. ${ }^{51,52}$ Electrons were excited by ultraviolet (UV) light from a semiconductor valence band to the conductance band, which then underwent electron transfer to oxygen to form ROS (mainly $\mathrm{OH})$ to kill the microorganisms. Various surface modifications, such as doping with molecules, could significantly enhance the antibacterial efficiency. For example, Pillai et al studied the photocatalytic antibacterial activity of fluorinated (F-doped) $\mathrm{ZnO}$ nanopowders against $E$. coli and $S$. aureus. ${ }^{53}$ Upon irradiation, F-doped $\mathrm{ZnO}$ nanopowders were more effective in inhibiting the growth of microorganisms than the undoped
ZnO nanopowders, showing $99.87 \%$ and $99.99 \%$ antibacterial activity against $E$. coli and $S$. aureus, respectively. ${ }^{53}$ Recently, Sethi et al fabricated $\mathrm{ZnO} / \mathrm{TiO}_{2}$ nanocomposites to combat $E$. coli. ${ }^{54}$ Compared to $\mathrm{ZnO}$ or $\mathrm{TiO}_{2}$ NPs alone, the $\mathrm{ZnO} / \mathrm{TiO}_{2}$ nanocomposite exhibited greater inactivation of $E$. coli under light irradiation. ${ }^{54}$ Among several different crystalline forms (anatase, rutile, and brookite), the anatase form was a better photocatalyst under UV light. ${ }^{55,56}$ Suketa et al revealed that coating nanostructured anatase $\mathrm{TiO}_{2}$ on the roughened implant surface exerted a bactericidal effect against dental periodontal pathogens Actinobacillus actinomycetemcomitans and Fusobacterium nucleatum. ${ }^{57}$ In addition, as mentioned previously, the addition of $\mathrm{KI}$ to $\mathrm{TiO}_{2}$ NPs that was excited by UVA strongly potentiated the broad-spectrum antimicrobial efficacy by up to 6 logs. ${ }^{58}$ Therefore, the bactericidal effect of photocatalysis for treatment of localized infections could be enhanced by spraying with a KI solution. ${ }^{58}$

Magnetic NPs $\left(\mathrm{MNPs}, \mathrm{Fe}_{3} \mathrm{O}_{4}\right)$, possessing a peroxidase-like activity, could be functionalized by conjugatively attaching PSs and other molecules to its surface to enhance the ROS generation at the targeted sites for aPDT applications. ${ }^{59,60}$ Multifunctional MNPs that were conjugated with PSs and vancomycin, ${ }^{61}$ and a composite system of reduced GO (rGO)-iron oxide NPs (rGO-IONP) ${ }^{62}$ can synergistically induce damage to methicillin-resistant Staphylococcus aureus (MRSA).

\section{Upconversion nanoparticles}

Most PSs were optimally excited with UV or short-wavelength blue light, whereas these wavelengths possessed inadequate tissue-penetration ability and may harm the human health. The NIR light ranging from 700 to 1100 $\mathrm{nm}$ had advantages of a deeper tissue penetration and lower autofluorescence, and can reduce side effects such as the phototoxicity and photodamage. ${ }^{63}$ Upconversion was a nonlinear optical process of two or more photons sequential absorption, leading to the emission of light at shorter wavelength than the excitation wavelength (antiStokes-type emission). ${ }^{20,64}$ Upconversion NPs (UCNPs) were able to absorb the NIR light and convert it into high energy photons, and could potentially be applied to solve the aforementioned limitations of traditional PDT.

Solid-state materials doped with lanthanide ions were proposed as promising alternatives to yield efficient upconversion energy for optical imaging, organic fluorophosphors, and PDT. Generally, "core-shell" structured composites covered by varieties of PSs were applied for aPDT against microorganisms. ${ }^{65-67}$ Recently, a multifunctional- 
nanostructured system UCNPs $\left(\mathrm{NaYF}_{4}: \mathrm{Mn} / \mathrm{Yb} / \mathrm{Er}\right) /$ Methylene blue (MB)/CuS-chitosan showed a superior antibacterial activity via synergistic effects of PDT/PTT. ${ }^{68}$ The bacteria-killing efficiency of this nanostructured system was up to $99 \%$ with $980 \mathrm{~nm}$ at $1 \mathrm{~W} \cdot \mathrm{cm}^{-2}$ for 20 mins. The red emission (650-670 nm) of UCNPs was applied to enhance the effectiveness of efficient energy transfer from UCNPs to MB. Then, the addition of $\mathrm{CuS}$ was to obtain a high therapeutic index via the synergistic effects of PDT/PTT. Finally, chitosan was grafted to prevent aggregations among the particles, thus providing an excellent water-solubility and biocompatibility. ${ }^{68}$

\section{Nanoparticles as nanocarriers for photosensitizers \\ AuNPs-based nanoparticles}

Gold NPs (AuNPs) earned significant attention due to its localized surface plasmon resonance (LSPR) upon light exposure. With LSPR having the absorption band of PSs, the absorption rate of the PSs was greatly enhanced by the high instantaneous electric field. This phenomenon could then lead to an increase in the PS excitation rate, which in turn increased the production of ROS. ${ }^{69}$ MB-conjugated AuNPs (MB-AuNPs) displayed excellent photoinactivation to combat 4-day biofilms of MRSA. Upon irradiation, the biofilm was reduced by over $5 \log _{10}$ using MB-AuNPs, while less than $1 \log _{10}$ using $\mathrm{MB}$ alone. ${ }^{70}$ Therefore, conjugating PSs on the surface of AuNPs was an effective approach to increasing the aPDT efficacy. ${ }^{70,71}$ In another study, core-shell nanostructured gold nanorods $/ \mathrm{SiO}_{2}$ with embedded verteporfin (AuNRs@SiO $\mathrm{SiO}_{2} \mathrm{VP}$ ) were synthesized for aPDT to target E. coli. ${ }^{72}$ Upon repeated irradiation, an infectious dose of $10^{4} \mathrm{CFU} / \mathrm{mL}$ E. coli was eradicated by AuNRs@ $\mathrm{SiO}_{2}-\mathrm{VP}$ at $710 \mathrm{~nm}\left(1 \mathrm{~W} / \mathrm{cm}^{2}\right)$. In addition, the irradiation time and the laser wavelength affected the efficiency of the nanostructures against pathogens. $^{72}$

\section{Silica-based nanoparticles}

Silica-based NPs were promising nanocarriers for PDT because of their excellent physical and chemical properties, good stability and dispersity, hydrophilicity, as well as biocompatibility. Functional groups could be attached to the surface of silica NPs (SiNPs), which enhanced them to capture numerous PDT drugs. ${ }^{73-75}$ Recently, Lin et al synthesized Ce6 loaded SiNPs with greater efficacy in inhibiting $S$. aureus and MRSA. The photostability of Ce6 molecules was significantly improved and maintained the ${ }^{1} \mathrm{O}_{2}$ generation capacity upon light illumination. ${ }^{76}$

\section{Liposomes}

Substantial attention was paid to liposomes as delivery systems for PSs in aPDT, since liposomes could improve the PS loading capacity as well as the PS' safety and selectivity. ${ }^{77-80}$ Liposomes consisted of one or more concentric lipid bilayers with a hydrophilic phase inside and between the bilayers. Therefore, PSs could be loaded into liposomes differently depending on the hydrophilicity or lipophilicity of PSs. ${ }^{77,78}$ Hydrophilic PSs were suspended in the aqueous inner phase of liposomes, whereas lipophilic PSs were dissolved in fatty side-chains in the interior of the lipid bilayer.

Once PSs were loaded into the liposomes, there were three uptake pathways for liposomal PSs into bacteria. The first pathway was the binding of the liposome to the bacterial cell and consequent migration of PSs from the lipid bilayer to the bacterial cell wall. The second pathway was based on the fusion of the liposome with the cell wall, followed by direct release of PSs into the bacteria. A third possibility was the release of PSs from the liposome into the surrounding medium and the diffusion of PSs through the cell wall. ${ }^{79,80}$ However, conventional liposomes had a short half-life circulation, which made it difficult to elevate the antimicrobial efficacy of PSs. ${ }^{77}$

PEG, a water-soluble polymer that exhibits protein resistance, was applied to stabilize and prolong the halflife of liposomes. The relative half-life of PEGylated liposomes was significantly increased ( $\sim 45 \mathrm{hrs})$, compared to conventional liposomes (a few hours). ${ }^{81}$ Cationic modification of liposomes was another promising way to enhance aPDT, since an overall cationic charge was necessary for PSs to have antimicrobial properties. ${ }^{82}$ Yang et al fabricated cationic liposomes embedded with cetyltrimethyl ammonium bromide (CTAB), in which Ce6 was encapsulated as PS to administer aPDT against clinical isolates of Candida albicans $\left(C\right.$. albicans). ${ }^{83}$ CTAB was a cationic compound with strong antimicrobial activity. However, it was unsuitable for direct usage due to its high affinity to biological membranes. Ce6 loaded CTAB-liposomal compounds showed greater aPDT efficacy against clinical drug-resistant strains of $C$. albicans in vitro. ${ }^{83}$ However, a major concern of cationic liposomes serving as antimicrobial PSs could be that the host cells might compete with the microorganisms for binding to the positively charged 
liposomes in the infected tissues, causing side effects upon illumination.

Recently, an enzyme-sensitive and PS-quenching lipidbased transfersomal carrier was developed to achieve better target selectivity, greater solubility, and skin penetration efficiency. ${ }^{84}$ In the absence of lipase, pheophorbide A (Pheo A) was self-quenched due to the mechanism of intramolecular interaction. However, when Propionibacterium acnes lipase-mediated disruption of nanocarrier occurred, Pheo A dequenching was selectively induced. Over $99 \%$ of Propionibacterium acnes was eliminated by the liposomemediated aPDT. ${ }^{84}$ As shown in Figure 2, free Pheo A was only detected in the stratum corneum because of its low solubility and high molecular weight, whereas Pheo Aloaded liposomes showed greater skin penetration efficiency. Furthermore, in vivo antibacterial effect of the liposomebased transfersomes in nude mice was also confirmed by a significant reduction in the swelling volume and thickness. ${ }^{84}$

\section{Polymer-based nanoparticles}

Polymer-based NPs possessed several advantages as drug delivery in $\mathrm{aPDT}^{85}:$ 1) flexibility in surface modification for better efficiency, 2) ability to prevent degradation of PSs in biological environment, 3) ability to load and deliver large amounts of PS to the target area, 4) excellent biocompatibility and biodegradability, and 5) ability to load multiple components such as targeting agents. Table 1 summarized recent studies using polymer-based NPs to apply in aPDT against different microorganisms.

PSs and other therapeutic agents could be co-loaded into the targeted polymer nanocarriers such as nanospheres, nanocapsules, and micelles, which allowed a precise and controlled delivery of the best drug ratio in the same area of the body. ${ }^{86}$ Recently, Xiao et al synthesized ubiquicidin (UBI)-loaded micelle to combat Pseudomonas aeruginosa (P. aeruginosa) in vitro and in vivo. ${ }^{87} \mathrm{UBI}$ was a positively charged antimicrobial peptide, which could bind to the negatively charged bacterial cell membrane but not mammalian cells. Therefore, it could selectively adhere to bacteria and depolarize the membrane to combine UBI with poly(butyl methacrylate)- $b$-poly(2(dimethylamino) ethyl methacrylate-co-eosin)- $b$-ubiquicidin [PBMA-b-P(DMAEMA-co-EoS)] (noted as PAMUBI) to form micelle. Moreover, upon light irradiation, ROS yielded from micelles could kill the bacteria (Figure 3) ${ }^{87}$ Hence, developing such polymeric nanocarriers was a promising alternative to apply in aPDT.

\section{Biosafety of nanomaterial-based aPDT in the oral cavity Non-toxic light source and biocompatible nanomaterial-loaded photosensitizers}

Light source and PSs were the two main components of aPDT application. UV light was proven to have excellent antibacterial efficacy on oral microorganisms. ${ }^{101}$ However, the irradiation of UV light could lead to DNA damage and UV-induced skin damage. ${ }^{102}$ In contrast, visible light and NIR light were regarded to be safe. On the other hand, a green and benign method was recommended as the biosynthesis method of PSs, ${ }^{103}$ and PSs would have a good bioactivity and biocompatibility with no dark toxicity or mutagenicity, with a high binding affinity for microorganisms and a low binding affinity and low toxicity for mammalian cells. ${ }^{104} \mathrm{In}$ addition, the irradiation intensity and dose of PSs should be controlled at a reasonable and effective range, where pathogens could be significantly reduced without damaging the host cells. To obtain a better therapeutic efficacy, a greater irradiation intensity, and a higher concentration of PSs were needed, which could result in thermal damage and tissue toxicity. ${ }^{105}$ Therefore, these parameters should be evaluated before biomedical applications in vivo. Commercial PSs such as aminolevulinic acid, Toluidine blue O (TBO), and MB have already been applied in clinical treatments for oral diseases approved by the Food and Drug Administration.

\section{Bioavailability of eco-friendly nanomaterials}

The bioavailability and biocatalytic activities of nanomaterials depended on their size and surface area, shape and aspect ratio, surface charge, composition and crystalline structure, aggregation and concentration, surface coating and roughness, and solubility. ${ }^{106}$ These physicochemical properties affect the toxicity at the cellular and tissue levels. Similarly, the efficient PS delivery, organ distribution, accumulation, retention, metabolism, degradation, and clearance should be considered at the organ level as well. ${ }^{107}$ Although many nanomaterials were developed, and some were used in clinical treatments, the understanding of the potential toxicity and the mechanisms of toxicity were limited. To obtain eco-friendly nanomaterials for a wide range of biomedical applications, all the parameters of nanomaterials should be strictly and repeatedly tested in animals first. Similarly, even for drugs that were effective in the short-term with no toxicity, long-term investigated were needed. Therefore, to address the eco-friendly concerns, good 


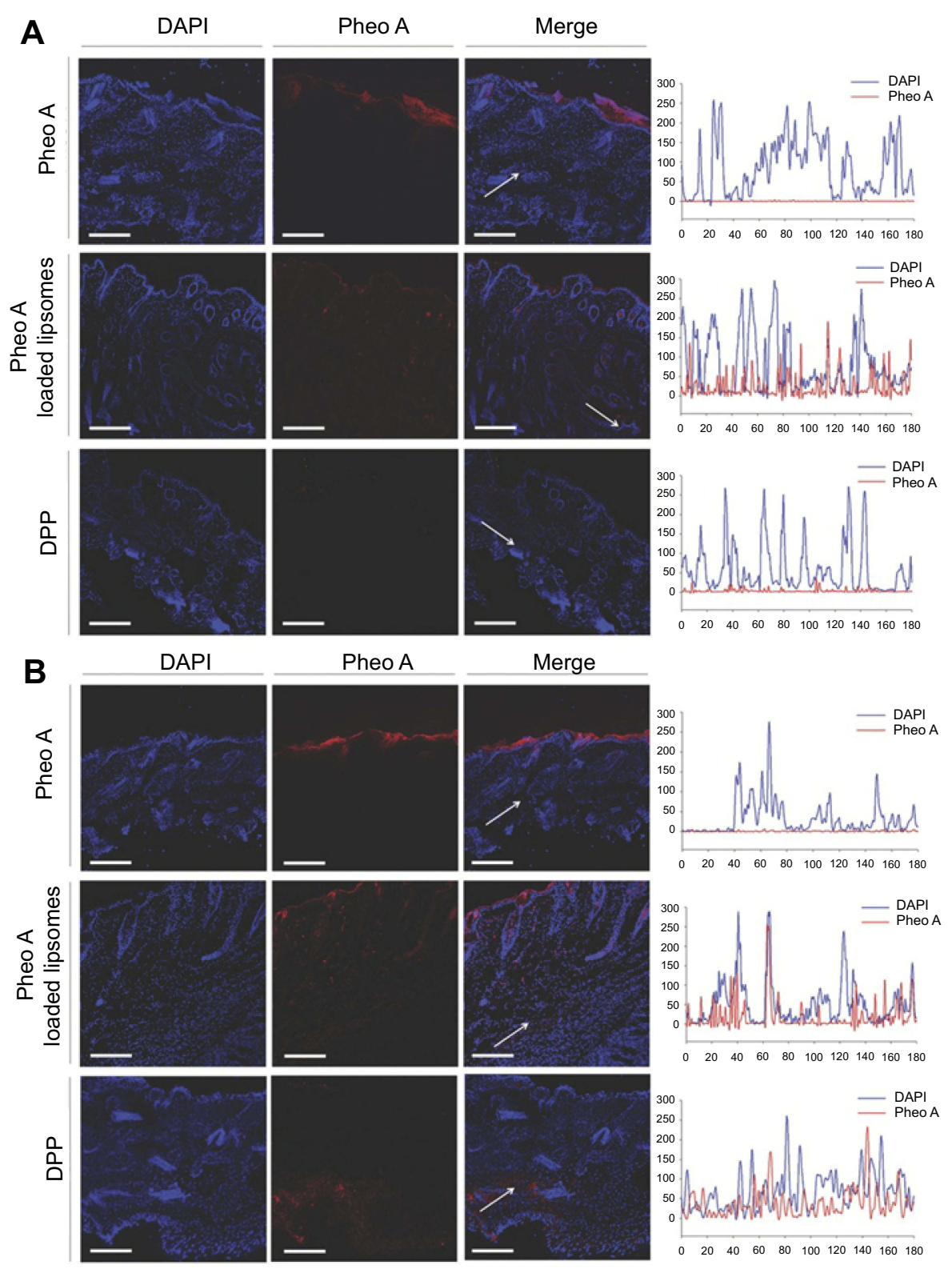

Figure 2 Confocal microscopy to compare skin penetration efficiency of free Pheo A, DPPC liposomes, and DPP transfersomes. The line scan data are shown by the white arrows in the images.

Notes: Cross-sections of (A) normal skin; and (B) P. acnes-induced skin were incubated on a Franz diffusion cell $(\mathrm{n}=3$ ). The blue signal indicates DAPI (nucleus; excitation/ emission: 358/46I nm). The red signal indicates Pheo A (excitation/emission: $410 \mathrm{~nm} / 675 \mathrm{~nm}$ ). Scale bar $=200 \mu$ m. Reprinted with permission from Park H, Lee J, Jeong S, et al. Lipase-sensitive transfersomes based on photosensitizer/polymerizable lipid conjugate for selective antimicrobial photodynamic therapy of acne. Adv Healthc Mater. 20I6;5 (24):3139-3147. ${ }^{84}$ Copyright (2016) John Wiley and Sons.

Abbreviations: DAPI, 4',6-diamidino-2-phenylinodle; DPP, DSPE-PEG-Pheo A; DPPC, dipalmitoylphosphatidylcholine; P. acnes, Propionibacterium acnes; Pheo A, pheophorbide A.

biocompatibility, biodegradability, and good solubility were needed for oral medicine applications.

\section{Application of aPDT in oral infectious diseases and treating the associated pathogens at the nanoscale}

This section introduced various oral infections and the related pathogens, as shown in Figure 4. Moreover, the cutting-edge researches on aPDT applications in oral infectious diseases and in treating the associated pathogens at the nanoscale were reviewed.

\section{Dental caries}

Dental caries is caused by acid production from biofilms. Among all the studies on aPDT against dental caries, Streptococcus mutans (S. mutans) is the most widely 


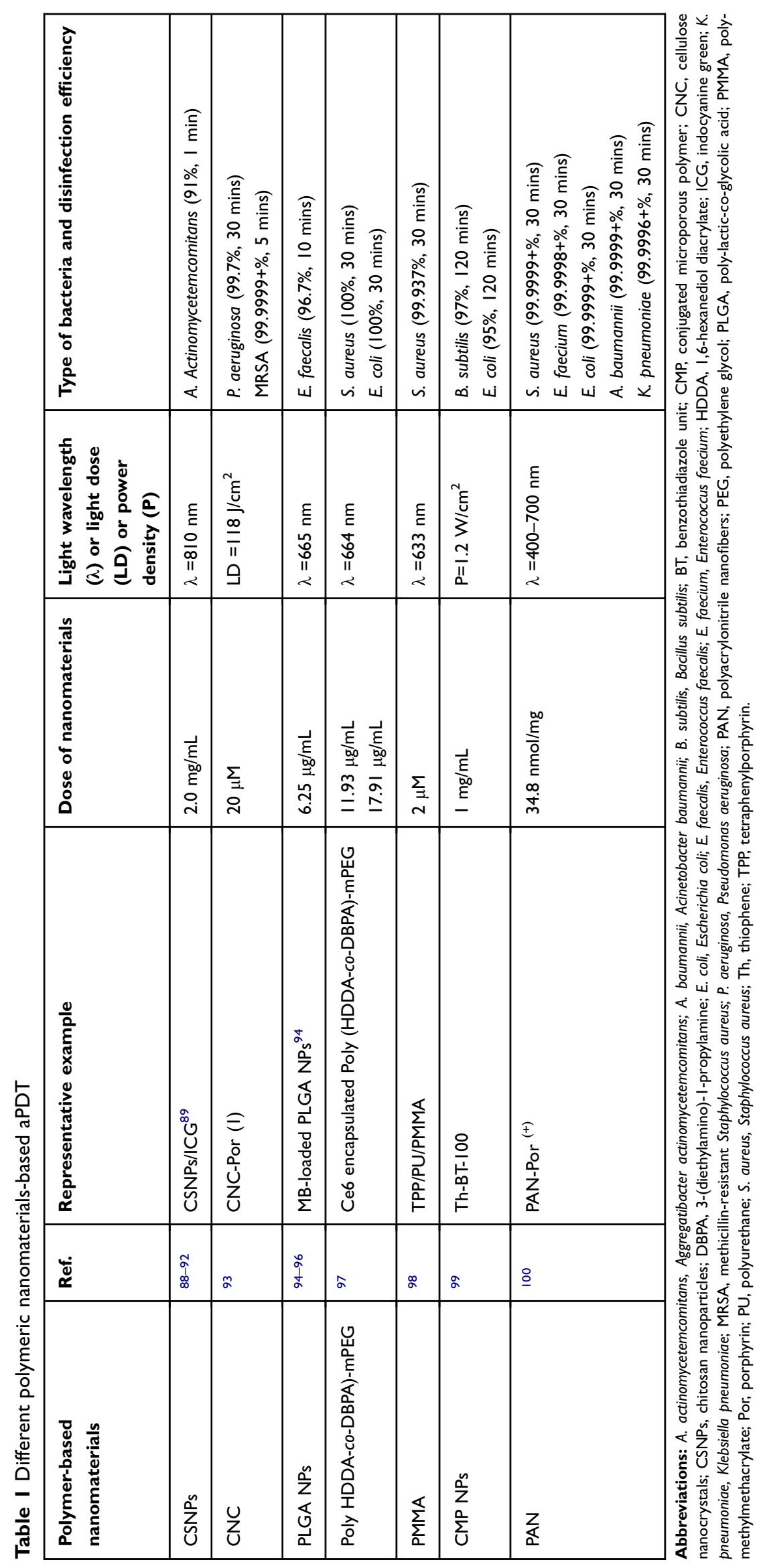




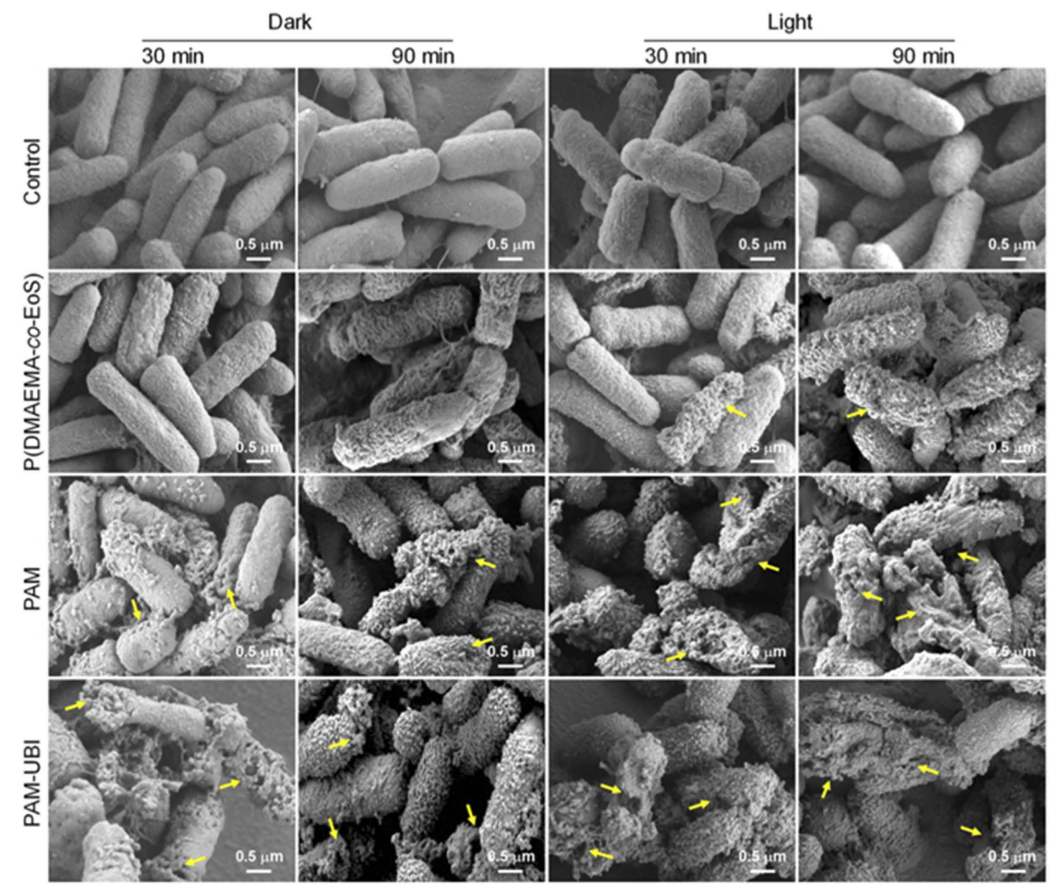

Figure 3 SEM images of $P$. aeruginosa after diverse treatment with different durations with or without light irradiation for 30 mins. Reprinted with permission from Xiao F, Cao B, Wang C, et al. Pathogen-specific polymeric antimicrobials with significant membrane disruption and enhanced photodynamic damage to inhibit highly opportunistic bacteria. The yellow arrows in the images showed the obvious membrane damage of the bacteria. ACS Nano. 2019;13(2):15II-1525. ${ }^{87}$ Copyright (2019) American Chemistry Society.

Abbreviations: P. aeruginosa, Pseudomonas aeruginosa; SEM, scanning electron microscope.

studied pathogens. ${ }^{108,109}$ Recently, conjugate-like nanocarriers were developed for PS loading. TBO-silver NP conjugates (TBO-AgNP) with a $70 \mathrm{~s}$ irradiation by $630 \mathrm{~nm}$ light showed a reduction of planktonic $S$. mutans by $4 \mathrm{log}$, compared to $2 \log$ by TBO alone. TBO-AgNP conjugates inhibited biofilm formation, increased the uptake of propidium iodide and increased the leakage of the cellular constituents. In addition, dextran-coated silver NPs $\left(\mathrm{AgNP}_{\mathrm{Dex}}\right)$ were used as an effective broad-spectrum antibacterial with no toxicity (Figure 5A). ${ }^{110}$

ICG was an effective adjunctive drug applied in wound healing and treatment for chronic infections of mucous membranes and skins with almost no host toxicity. ${ }^{111}$ Gholibegloo et al synthesized various nanocarriers including GO, GOcarnosine (GO-Car), and GO-Car/Hydroxyapatite (HAp) for ICG loading and investigated antibacterial effects in aPDT against S. mutans (Figure 5B). ${ }^{112}$ GO@ICG, GO-Car@ICG, and GO-Car/HAp@ICG mediated aPDT, reduced S. mutans counts by $91.2 \%, 95.5 \%$, and $93.2 \%$, respectively, and suppressed $S$. mutans biofilm by $51.4 \%, 63.8 \%$, and $56.8 \%$, respectively. GO-Car/HAp@ICG showed the greatest amount of ICG loading as well as the longest time stability, which could promote the efficiency of aPDT for treating local dental infections. ${ }^{112}$

\section{Endodontic root canal infections}

Endodontic infections include primary or secondary root canal infection, persistent root canal infection, and extraradicular infection. ${ }^{113}$ Enterococcus faecalis (E. faecalis) and Porphyromonas gingivalis (P. gingivalis) were detected in $49 \%$ and $17.6 \%$ in primary endodontic infection, respectively. ${ }^{114}$ E. faecalis, the predominant bacteria leading to the failure of endodontic treatments, was also associated with other oral diseases, such as caries, periodontitis, and peri-implantitis. ${ }^{115}$ Sodium hypochlorite $(\mathrm{NaOCl})$ was an effective irrigating solution to disrupt biofilms in root canals. However, $2.5 \% \mathrm{NaOCl}$ could not completely eliminate biofilms due to the anatomical complexities. In addition, $\mathrm{NaOCl}$ could cause negative effects on dentin hardness, ${ }^{116}$ bond strength, and marginal adaptation. ${ }^{117}$

Recently, a novel PS (rose bengal-functionalized chitosan NPs [CSRBnp]) was developed for root canal disinfection to eliminate single bacteria, monospecies, and multispecies biofilm (Figure 5C). ${ }^{118,119}$ E. faecalis was reduced by $50-65 \%$ with CSRBnp in the dark and was rapidly eradicated with CSRBnp after aPDT. In the presence of inhibitors, dentin, and LPS, the antibacterial efficacy of CSRBnp was reduced in the initial hours, but the bacteria were eradicated after $24 \mathrm{hrs}$. The pulpal tissues showed the highest inhibitory effect, followed 


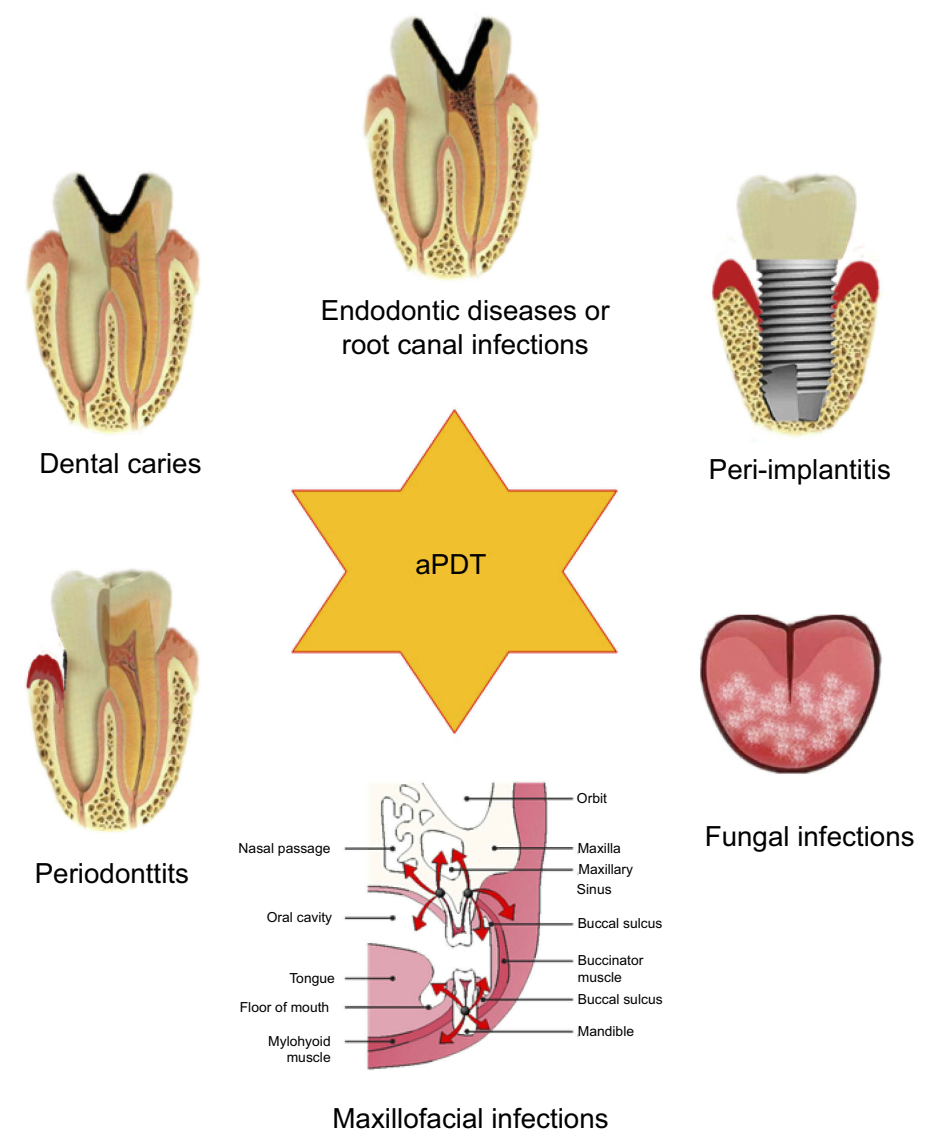

Figure 4 Schematic diagram of the application of aPDT in dentistry. APDT had potential to inhibit many oral infections including caries, endodontic diseases, root canal infections, periodontitis, peri-implantitis, oral fungal infections and maxillofacial infections.

Abbreviation: aPDT, antimicrobial photodynamic therapy.

by BSA. CSRBnp had 40-65\% bacterial reduction after 24 hrs. ${ }^{118}$ The CSRBnp-mediated aPDT disturbed the multilayered biofilm architecture of E. faecalis and improved the resistance to degradation and mechanical strength of dentinal collagen. ${ }^{120}$ After exposure to aPDT, the bacterial membrane damage was verified by atomic force microscopy. ${ }^{119}$ Furthermore, multispecies biofilms of Streptococcus oralis, Prevotella intermedia, and Actinomyces naeslundii on the dentin were subjected to $60 \mathrm{~J} / \mathrm{cm}^{2}$ and were completely disturbed, reducing the biofilm thickness. ${ }^{119}$ The mechanism of aPDT with CSRBnp was likely that NPs inactivated the endotoxins and lipopolysaccharides, and reduced the expression of inflammatory factors by activating the macrophages, without cytotoxic effect on the cells. $^{121}$

In a recent study, ICG was placed into nano-GO (NGO) to produce NGO-ICG, which was more effective for aPDT against $E$. faecalis than using ICG alone (Figure 5D). ${ }^{122}$ NGO-ICG-PDT reduced the viability of E. faecalis by $2.8 \mathrm{log}$, and reduced the biofilm of $E$. faecalis by $99.4 \%$ at an energy density of $31.2 \mathrm{~J} / \mathrm{cm}^{2}$. NGO-ICG-PDT with a lower concentration of ICG (200 $\mu \mathrm{g} / \mathrm{mL})$ showed better antibacterial effect than ICG-PDT with a concentration of ICG $(1000 \mu \mathrm{g} / \mathrm{mL})$ both in overall antimicrobial and anti-biofilm potential (47\% and $21 \%$, respectively). Furthermore, Afkhami et al compared the efficacy of AgNPs/100 ppm (AN), an $810 \mathrm{~nm}$ diode laser (DL), ICG-based PDT (ICG/DL), ICG-modified AgNPsbased PDT (AN/ICG/DL), and conventional irrigant $\mathrm{NaOCl}$, against $E$. faecalis. ${ }^{123}$ AN/ICG/DL had the greatest reduction of $99 \%$ in colony counts, followed by DL group with $97 \%$ reduction. $\mathrm{AN}$ and $\mathrm{NaOCl}$ groups had $94.42 \%$ and $94.61 \%$ reduction, respectively, whereas ICG/ DL group had only $68.47 \%$ reduction. ${ }^{123}$ In addition, different ICG-loaded metal-organic frameworks (MOFICG) including Al-101-ICG, Fe-88-ICG, and Fe-101-ICG were designed to improve the properties of ICG and the antimicrobial activity for aPDT against endodontic infections (Figure 5E). ${ }^{124}$ After $810 \mathrm{~nm}$ laser irradiation, the viability of $E$. faecalis could be suppressed by ICG-free MOFs by $18.1 \%, 28.8 \%$, and $38.3 \%$, via Al-101, Fe-88, and Fe-101, respectively. MOF-ICG-based aPDT reduced the count of E. faecalis by $60.72 \%, 45.12 \%$, and $62.67 \%$, 

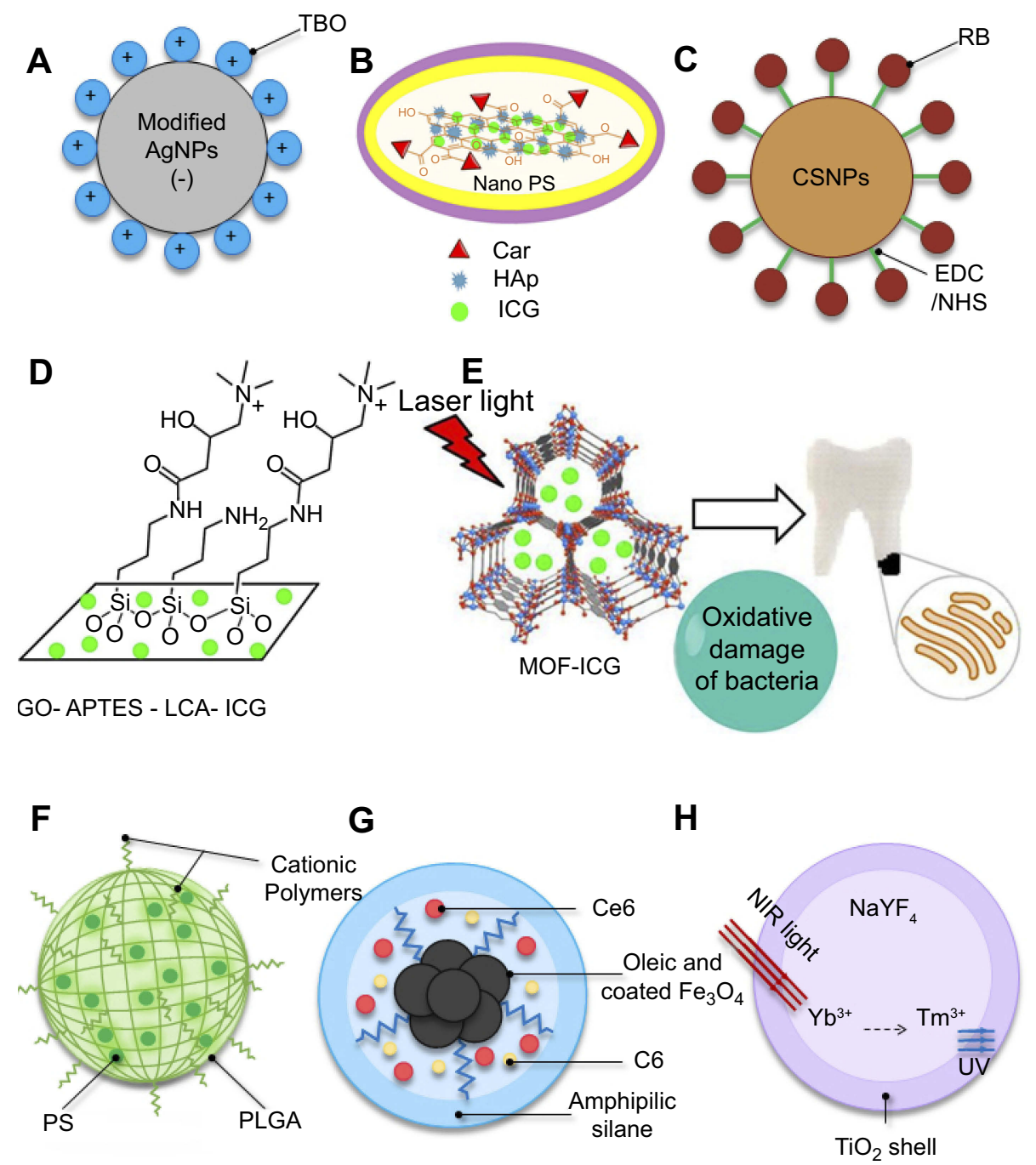

Figure 5 Proposed structures of nanomaterials against dental caries, endodontic infections and periodontal diseases.

Notes: (A) TBO-AgNP; (B) GO-Car/HAp@ICG; (C) CSRBnp with EDC and NHS; (D) NGO-ICG; (E) MOF-ICG and antibacterial mechanism; (F) MB-loaded PLGA cationic $\mathrm{NPs}$; (G) antibacterial multifunctional NPs Fe $\mathrm{O}_{4}$-silane@Ce6/C6; and (H) UCNPs@TiO 2 and upconversion processes. Reprinted from Gholibegloo E, Karbasi A, Pourhajibagher $\mathrm{M}$, et al. Carnosine-graphene oxide conjugates decorated with hydroxyapatite as promising nanocarrier for ICG loading with enhanced antibacterial effects in photodynamic therapy against Streptococcus mutans. J Photoch Photobio B. 2018;18I:14-22, 'I2 Copyright (2018), with permission from Elsevier for Figure 5B. Reprinted from Akbari T, Pourhajibagher M, Hosseini F, et al. The effect of indocyanine green loaded on a novel nano-graphene oxide for high performance of photodynamic therapy against Enterococcus faecalis. Photodiagn Photodyn. 2017;20:148-153, ${ }^{122}$ Copyright (2017), with permission from Elsevier for Figure 5D. Reprinted with permission from Golmohamadpour A, Bahramian B, Khoobi M, Pourhajibagher M, Barikani HR, Bahador A. Antimicrobial photodynamic therapy assessment of three indocyanine green-loaded metal-organic frameworks against Enterococcus faecalis. Photodiagn Photocyn. 2018;23:33I-338. ${ }^{124}$ Copyright (20I8), with permission from Elsevier for Figure 5E.

Abbreviations: AgNP, silver nanoparticle; PS, photosensitizer; Car, carnosine; CSRBnp, rose bengal functionalized chitosan nanoparticles; EDC, N-ethyl-N'-(3-dimethyl aminopropyl) carbodiimide; GO, Graphene oxide; HAp, hydroxyapatite; ICG, indocyanine green; MB, Methylene blue; MOF, metal-organic frameworks; NGO, nanoGraphene oxide; NHS, N-Hydroxysuccinimide; NPs, nanoparticles; PLGA, Poly lactic-co-glycolic acid; TBO, Toluidine blue O; UCNPs, upconversion nanoparticles.

respectively. Biofilms were dramatically decreased by $53.68 \%, 37.54 \%$, and $47.01 \%$, respectively. The expression of biofilm-associated esp gene was remarkably reduced by $6.0,4.4$, and 6.2 folds, respectively. ${ }^{124}$

\section{Periodontitis and peri-implantitis}

MB-loaded PLGA cationic NPs showed great antimicrobial effects against biofilms of microorganisms from untreated patients with chronic periodontitis (Figure 5F). ${ }^{125}$ After a 5- min irradiation with red light $\left(100 \mathrm{~mW} / \mathrm{cm}^{2}\right)$, these NPs reduced the bacterial activity of microorganisms in planktonic and biofilm phase by approximately $60 \%$ and $48 \%$, respectively. ${ }^{125}$ ICG-loaded nanospheres were coated with chitosan (ICG-Nano/c) to eradicate Porphyromonas gingivalis. ${ }^{126}$ ICG-Nano/c with positive charge on the surface could adhere to the surface of Gram-negative bacteria, Porphyromonas gingivalis and the bacterial viability was reduced by $2 \log _{10}(96.71 \%)$ to $4 \log _{10}(99.99 \%){ }^{126}$ 
Remarkably, the approach of intermittent irradiation with air cooling improved the therapeutic penetration, and the tissue thermal damage was avoided. ${ }^{127}$

Multifunctional NPs $\quad \mathrm{Fe}_{3} \mathrm{O}_{4}$-silane@Ce6/C6 were developed to trigger the aPDT against periodontitis-related pathogens (Figure 5G). ${ }^{128}$ The NPs were stable and biocompatible without cytotoxicity. The NP-based aPDT could reduce three single-species periodontitis-related biofilm by about 4-5 orders of magnitude after 3 mins irradiation of the $630 \mathrm{~nm}$ light $\left(100 \mathrm{~mW} \cdot \mathrm{cm}^{-2}\right)$. In addition, the addition of $\mathrm{C} 6$ and $\mathrm{Fe}_{3} \mathrm{O}_{4}$ realized the real-time monitoring and magnetic targeting functions. ${ }^{128}$

P. gingivalis was predominant in pockets of deeper than 4 $\mathrm{mm} .{ }^{129}$ Therefore, another consideration for aPDT to target periodontitis was for the light source to penetrate deep enough to reach the bottom of the periodontal pocket. In a recent study, we synthesized core-shell-structured NPs of $\mathrm{NaYF}_{4}: \mathrm{Yb}^{3+}$, $\mathrm{Tm}^{3+} @ \mathrm{TiO}_{2}\left(\mathrm{UCNPs} @ \mathrm{TiO}_{2}\right)$ triggered by NIR light in aPDT for treating periodontitis-associated pathogens (Figure 5H). The UCNPs@ $@ \mathrm{TiO}_{2}$-based aPDT reduced the three single-species biofilm CFU by approximately 4 orders of magnitude. After 5 mins of initial irradiation of $2.5 \mathrm{~W} \cdot \mathrm{cm}^{-2}$, the planktonic bacteria was eliminated via $2 \mathrm{mM}$ at the 4 th hour. The UCNPs@TiO ${ }_{2}$-mediated aPDT had great potential for effective periodontitis treatment.

Peri-implantitis was defined as an inflammatory process which affected the tissues around an osseointegrated implant and eventually contributed to the loss of supporting bone. Although multiple factors could result in implant failure, a large number of evidences showed that anaerobic plaque bacteria had the detrimental effect on peri-implant tissue health. ${ }^{130}$ Like periodontitis, plaque was the initiator of peri-implantitis.

Although there were few reports about nanomaterialsbased aPDT for treating peri-implantitis, nanosurface layer showed promising in infection-prevention. Surface nanocoatings on implants with silver, titanium dioxide, and hydroxyapatite (HA) were created by silver plating, anodization, and sintering techniques. The dual-layered silvernHA nanocoating completely inhibited the bacterial growth in the surrounding media and reduced the biofilm on the surface of implants by $97.5 \%$. This novel nanocoating to titanium alloy implants offered a lower infection risk, osseointegration, and accelerated bone healing. ${ }^{131}$

\section{Oral fungal infections}

Oral candidiasis was an oral mucosal disease caused by fungal candidiasis. Candida species were the most common fungi isolated from the oral cavity of both healthy and sick people. Under certain conditions, the Candida species in the symbiotic relationship could turn into a pathogenic state, which could contribute to its growth. The pathogenesis of candidiasis involved three factors: host factors, fungus, and oral microenvironment changes. ${ }^{132}$ Oral microenvironment changes included an improper denture, overuse of antibiotics, poor oral hygiene, smoking, and alcohol abuse. ${ }^{132}$ Oral infections caused by $C$. albicans were usually superficial and had different clinical manifestations. However, if not treated, it could spread to the throat, digestive tract and respiratory tract, and could be complicated by fungal sepsis, endocarditis, meningitis, and other serious complications. ${ }^{133}$ Currently, broad-spectrum antibiotics were used to treat oral candidosis. However, Candida biofilms showed resistance to both antimicrobial mouthwashes and traditional antifungal agents. ${ }^{134}$

Various conjugates of PSs with AuNPs were developed to combat C. albicans. ${ }^{135}$ The conjugates of aluminum phthalocyanine (complex 1) with gold nanorods (complex 1-AuNRs) and bipyramids (complex 1-AuBPs) showed a strong antifungal and bactericidal activity. ${ }^{135}$ Under a power density of $92 \mathrm{~mW} \cdot \mathrm{cm}^{-2}$ at $691 \mathrm{~nm}$, complex 1 alone had a $1.78 \mathrm{CFU} \log$ reduction, whereas complex 1AuBPs and complex 1-AuNRs had 2.08 and $2.53 \mathrm{log}$ reductions, respectively. ${ }^{135}$ AuNPs conjugated to MB or TBO were found to effectively combat both $C$. albicans planktonic cells and biofilms. In vivo, the mixture of AuNPs conjugated to two different PSs depleted the hyphal C. albicans burden against superficial skin and oral $C$. albicans infection in mice with a total light dose of $21.6 \mathrm{~J} / \mathrm{cm}^{2}$ at $662 \mathrm{~nm}$ as well as $635 \mathrm{~nm}$, respectively. ${ }^{136}$

Erythrosine (Ery) was used to kill oral microorganisms such as $S$. aureus, S. mutans, and C. albicans. ${ }^{137} \mathrm{TiO}_{2}$ NPs, as a catalyst, enhanced the activity of PSs. Ery gel, when combined with $\mathrm{TiO}_{2}$ stimulated by blue light (BL) with $15 \mathrm{~J} / \mathrm{cm}^{2}$, had greater fungicidal activity than $0.12 \%$ chlorhexidine. The treatments of $220 \mu \mathrm{M}$ Ery gel $+1 \%$ $\mathrm{TiO}_{2}+\mathrm{BL}$ and of $440 \mu \mathrm{M}$ Ery gel $+1 \% \mathrm{TiO}_{2}+\mathrm{BL}$ reduced the Candida CFU by 1.27 and 1.85 logarithmic orders, respectively. ${ }^{137}$

\section{Maxillofacial infections}

Traditionally, maxillofacial infections were treated with antibiotic therapy. However, the overuse of antibiotics could cause bacterial resistance and even multidrug-resistant (MDR) species. S. aureus and P. aeruginosa were the 
two most common organisms in both acute and chronic wounds, and MRSA were the majority of all superficial skin infections. ${ }^{138}$ Recently, a novel organic-inorganic hybrid coating (Tannic Acid/Fe $\mathrm{Fe}^{3+} / \mathrm{AgNPs}$ ) was developed to mitigate implant-related bacterial infection (Figure 6). ${ }^{139}$ Under $660 \mathrm{~nm}$ visible light for $20 \mathrm{mins}$, the antibacterial ratio of $\mathrm{TA} / \mathrm{Fe}^{3+} / \mathrm{AgNPs}-5$ was $92 \%$ and $87 \%$ against $E$. coli and $S$. aureus, respectively. The corresponding values of $\mathrm{TA} / \mathrm{Fe}^{3+} / \mathrm{AgNPs}-10$ were nearly $100 \%$ and $94 \%$, respectively. ${ }^{139}$ Upconversion nanoconstructs, consisting of the cationic N-octyl chitosan (OC), $\mathrm{NaYF}_{4}: \mathrm{Yb}, \mathrm{Er} @ \mathrm{NaYF}_{4}$ (UCNPs), and zinc phthalocyanine (ZnPc) (OC-UCNP-ZnPc), showed excellent antibacterial efficacy with NIR irradiation for the MDR bacteria including MRSA and $\beta$-lactamase-producing $E$. coli in vitro (Figure 7). ${ }^{140}$ OC-UCNP-ZnPc-based aPDT had better antibacterial activity than the well-known positive drug vancomycin. OC-UCNP-ZnPc-based PDT against MRSA showed $0 \%$ viability at $250 \mu \mathrm{g} \mathrm{mL}^{-1}$ and had similar antibacterial activity against $\beta$-lactamase-producing $E$. coli. Significant reduction in the abscess volume of the subjected mice using $980 \mathrm{~nm}$ irradiation was observed in vivo. $^{140}$

Novel multifunctional NIR-sensitive NO delivery nanoplatform Roussin's black salt@ $\mathrm{NaGdF}_{4}: \mathrm{Yb}$ / Tm@mSiO $2 @$ quaternized ammonium chitosan (RBS @UCNP@mSiO $2 @ q C)$ under NIR irradiation was developed for eradication of MRSA biofilms (Figure 8). ${ }^{141}$ The eradication of drug-resistant bacterial biofilms was up to $78 \%$ by treating with RBS@UCNP@mSiO $\mathrm{m}_{2} @ \mathrm{qC}$ via NIR irradiation at 200 $\mu \mathrm{g} \cdot \mathrm{mL}^{-1}$. In vivo, 13 medical catheters pre-colonized with the biofilms of $S$. aureus were implanted subcutaneously in rats to simulate implant-related peri-
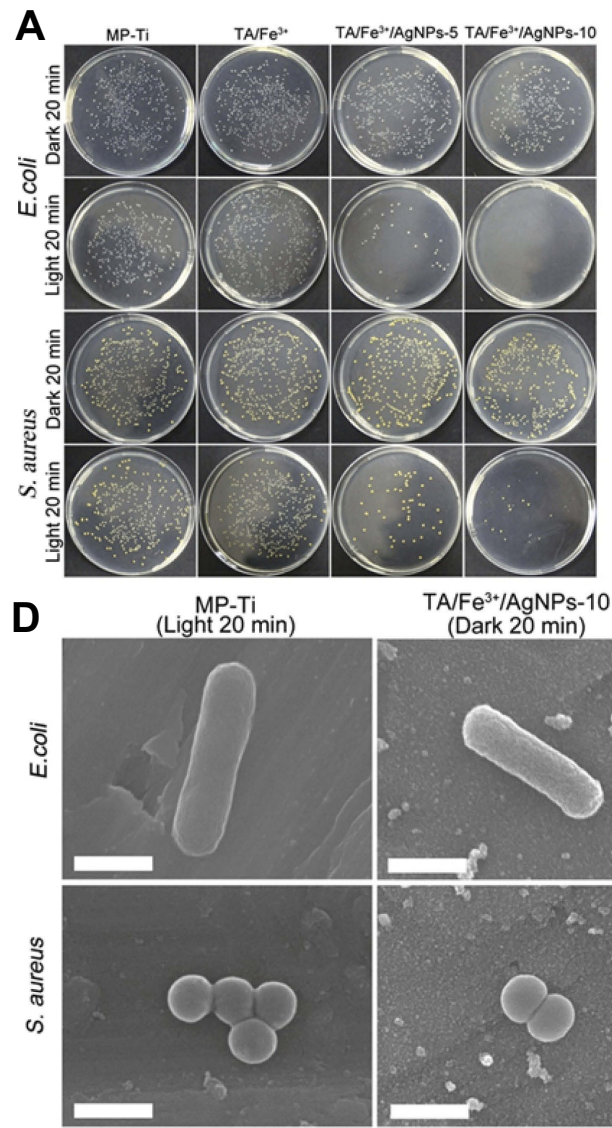

B

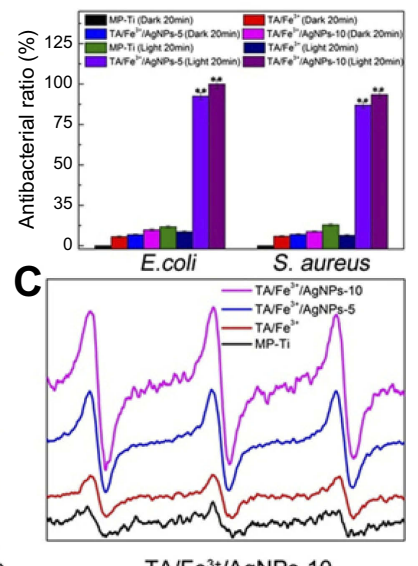

TA/Fe ${ }^{3+} / \mathrm{AgNPs}^{-10}$

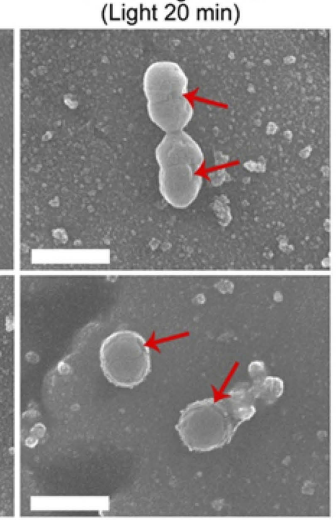

Figure 6 (A) Plate samples showing colonies of E. coli and S. aureus under $660 \mathrm{~nm}$ visible light for 20 mins or in the dark. (B) Antibacterial ratio determined according to the number of colonies in the plate samples $* * P<0.01$ vs Ti group as control. (C) ESR signals of ${ }^{\prime} \mathrm{O}_{2}$ obtained upon irradiation of different samples for 20 mins in the presence of TEMP. (D) Morphologies of $E$. coli and S. aureus seeded on MP-Ti and TA/Fe ${ }^{3+} / \mathrm{AgNPs}-10$ under the illumination of $660 \mathrm{~nm}$ visible light for $20 \mathrm{~min}$ (scale bar $=\mathrm{I} \mu \mathrm{m}$ ). The red arrows in (D) indicated the portions of the membrane were shrunk, and several parts were completely broken. Reprinted with permission from Xu Z, Wang $X$, Liu X, et al. Tannic acid/Fe ${ }^{3+} / \mathrm{Ag}$ nanofilm exhibiting superior photodynamic and physical antibacterial activity. ACS Appl Mater Inter. 2017;9(45):39657-3967I. ${ }^{139}$ Copyright (20I7) American Chemistry Society.

Abbreviations: E. coli, Escherichia coli; ESR, electron spin resonance; MP-Ti, mechanically polished Ti plates; S. aureus, Staphylococcus aureus; TEMP, 2,2,6,6tetramethylpiperidine. 


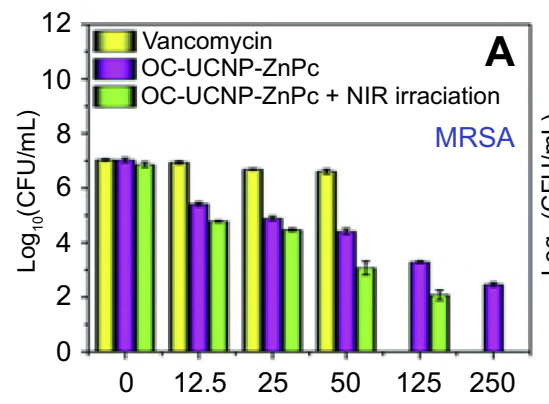

Concentration of OC-UCNP-ZnPc $(\mu \mathrm{g} / \mathrm{mL})$

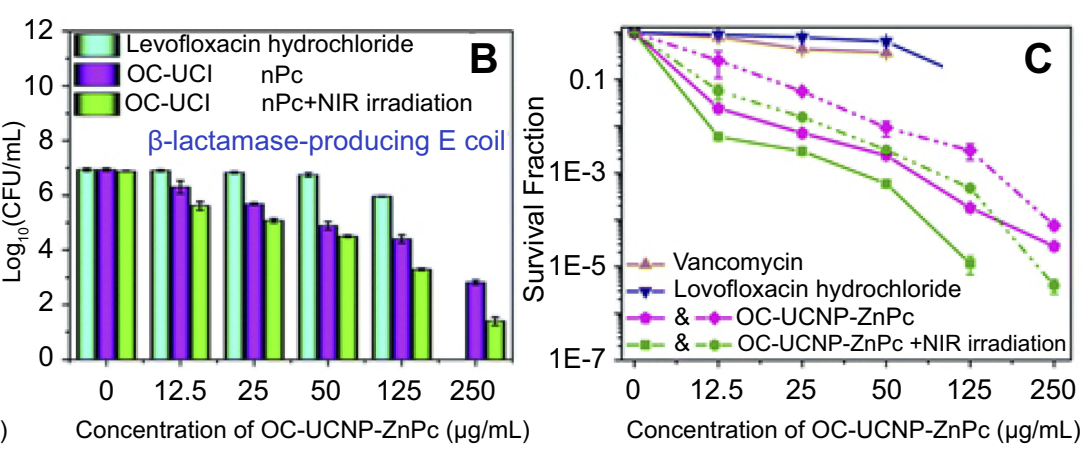

Concentration of OC-UCNP-ZnPc $(\mu \mathrm{g} / \mathrm{mL})$
Concentration of OC-UCNP-ZnPc $(\mu \mathrm{g} / \mathrm{mL})$
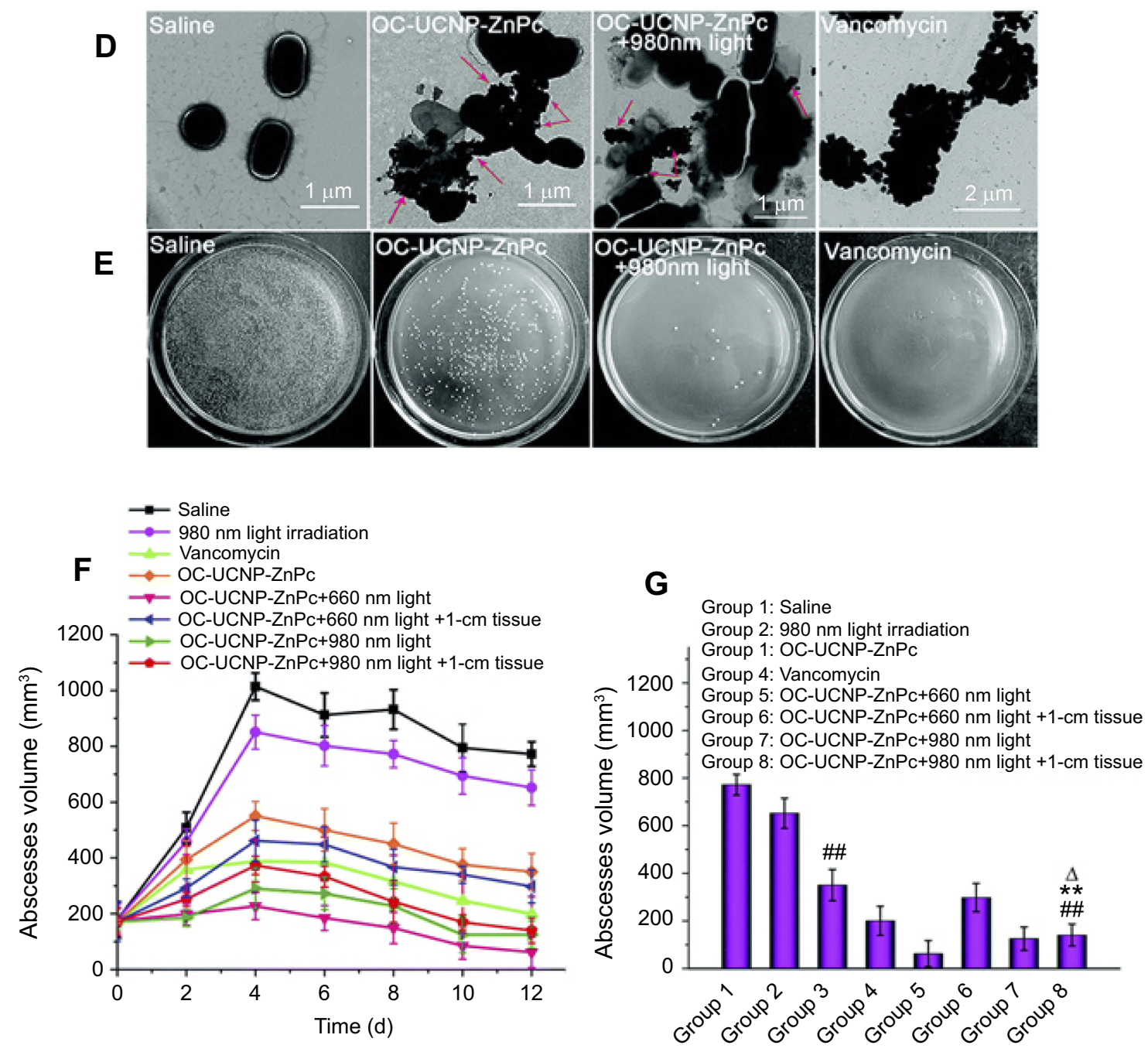

Figure 7 (A-E) Antibacterial effects of OC-UCNP-ZnPc on MDR bacteria in vitro. Viability of (A) MRSA and (B) $\boldsymbol{\beta}$-lactamase-producing E. coli after incubation with OCUCNP-ZnPc at different concentrations with/without NIR irradiation; (C) antibacterial effects induced by the nanoconstructs on MRSA (solid line) and $\boldsymbol{\beta}$-lactamaseproducing E. coli (dotted line); (D) TEM images, and (E) photographs of plate samples of MRSA in control, OC-UCNP-ZnPc (I $25 \mu \mathrm{mL} \mathrm{mL}^{-1}$ ) group without NIR irradiation, $980 \mathrm{~nm}$ light-triggered PDT group, and vancomycin $\left(125 \mu \mathrm{g} \mathrm{mL}{ }^{-1}\right)$ positive control. OC-UCNP-ZnPc nanoconstructs could be observed in TEM of OC-UCNP-ZnPc groups (the red arrows). (F-G) Anti-MRSA efficacy of OC-UCNP-ZnPc nanoconstructs in vivo. (F) Changes in the volume of MRSA-infected skin abscesses; (G) in vivo anti-MRSA efficacy of different groups at day 12. Statistical significance was determined by a Student's $t$ test (\#\# 0.01 for the OC-UCNP-ZnPc treatment group and the $980 \mathrm{~nm}$ light triggered deep-tissue PDT treatment group compared with the control group; **P< 0.01 for the 980 nm light triggered deep-tissue PDT group compared with the OCUCNP-ZnPc treatment group without $980 \mathrm{~nm}$ light irradiation; $\Delta P<0.05$ for the $980 \mathrm{~nm}$ light triggered deep-tissue PDT group compared with the $660 \mathrm{~nm}$ light induced deep-tissue PDT group). Republished with permission of RSC Pub, from Li S, Cui S, Yin D, et al. Dual antibacterial activities of a chitosan-modified upconversion photodynamic therapy system against drug-resistant bacteria in deep tissue. Nanoscale. 2017;9(II):3912-3924. ${ }^{140}$ Copyright (20I7) Royal Society of Chemistry. Permission conveyed through Copyright Clearance Center, Inc.

Abbreviations: E. coli, Escherichia coli; MDR, multi-drug resistant; MRSA, methicillin-resistant Staphylococcus aureus; NIR, near-infrared; OC, N-octyl chitosan; TEM, transmission electron microscope; UCNP, upconversion nanoparticle; $\mathrm{ZnPc}$, zinc phthalocyanine. 


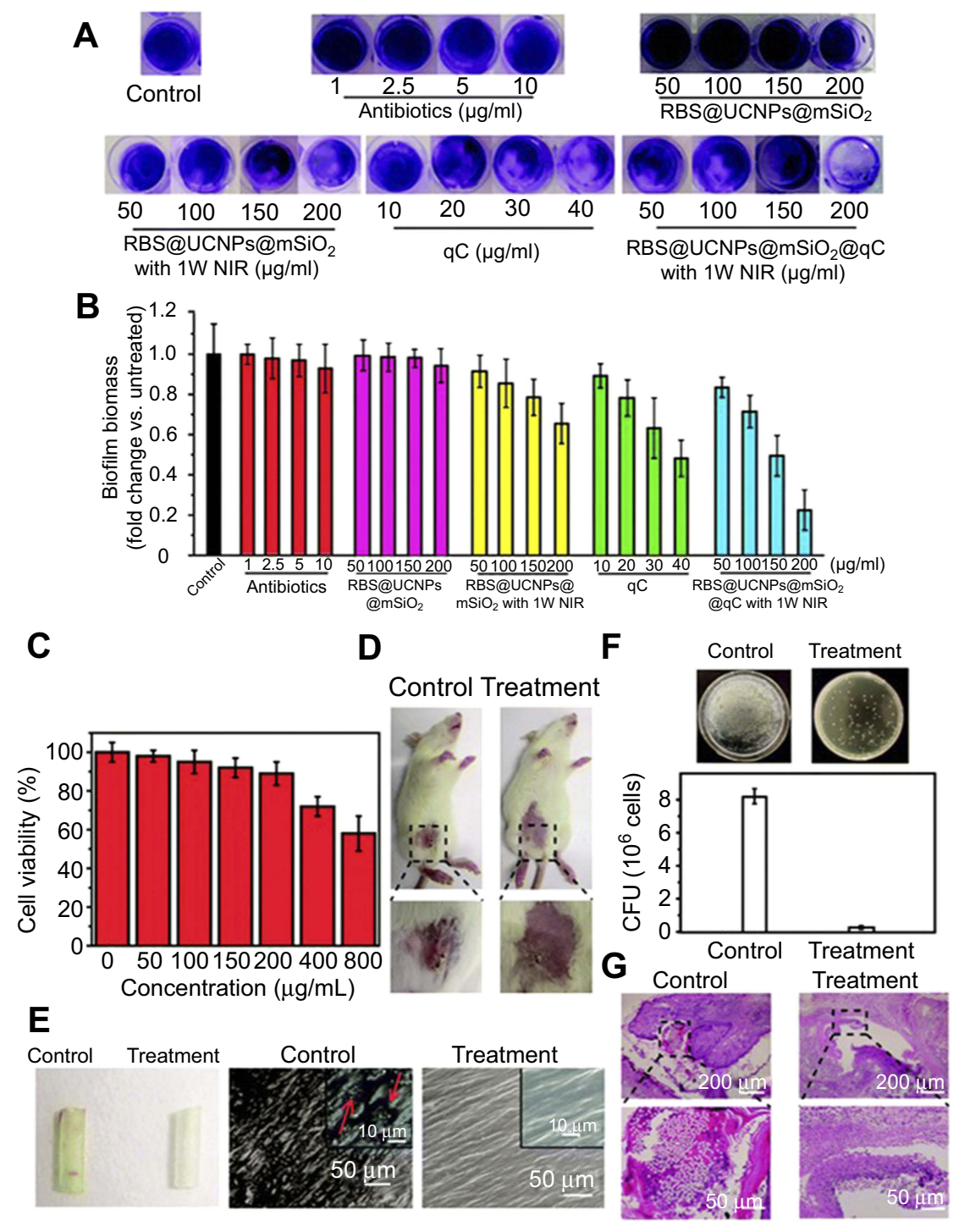

Figure 8 (A) Photographs of biofilms. (B) Quantifying the eradication of antibiotic-resistant biofilms by crystal violet staining treatment with various agents $(\mathrm{n}=5$ ). $(\mathbf{C})$ Viabilities of HeLa cells vs increasing concentrations of RBS@UCNP@mSiO ${ }_{2} @ q C N P s .(D)$ Synergistic dispersal of biofilms in vivo. (E) Implanted catheters and the surface of embedded catheters observed by SEM. The inset of (E) shows the magnified images. The red arrows indicate the biofilms on the embedded catheters. (F) CFU in vivo in the control and treatment group. (G) Histological analysis of tissues around implants. Each group had 5 rats $(n=5)$. Republished with permission of Royal Society of Chemistry, from Dong K, Ju E, Gao N, Wang Z, Ren J, Qu X. Synergistic eradication of antibiotic-resistant bacteria based biofilms in vivo using a NIR-sensitive nanoplatform. Chem Commun. 2016;52(30):5312-5315. ${ }^{141}$ Permission conveyed through Copyright Clearance Center, Inc.

Abbreviations: CFU, colony-forming units; qC, quaternized ammonium chitosan; RBS, Roussin's black salt; SEM, scanning electron microscope; UCNP, upconversion nanoparticle.

prosthetic infections. The wounds of rats in the nanocompounds-based aPDT group formed scabs and gradually healed after 7 days. In addition, there were few bacteria and no biofilms on the embedded catheters in the nanocompounds-based aPDT group, suggesting that the biofilm was indeed eradicated. Neither detectable signs of infection nor bacteria were observed in the implanted site in the histological slices of hematoxylin and eosin staining. ${ }^{141}$ Therefore, the UCNP-based NIR light system offered significantly improved penetration depth and was effective for potential therapeutic applications to prevent maxillofacial infections.

\section{Conclusion}

This article reviewed recent cutting-edge research on antibacterial PDT based on nanostructured materials in the field of dentistry. This included the nanostructured PS modification for aPDT enhancement and the therapeutic effects on oral infectious diseases, including caries, periodontitis, peri-implantitis, endodontic infections, and oral 
fungal infections. Since the majority of oral infections were located in deep sites, the challenge was for the drugs to reach the deep pockets and be maintained at an effective concentration for the infection. Different types of nanostructured materials were designed to be triggered by UV light, visible light, and NIR light for effective ROS generation. Based on these technologies, the antibacterial PDT exerted superior effects on microorganism-based oral diseases such as caries, periodontitis, peri-implantitis, oral fungal infections, and endodontic infections. Therefore, this novel therapeutic approach demonstrated the exciting potential for applications in dentistry, especially for infections located in deep pockets.

\section{Acknowledgments}

This study was supported by Natural Science Foundation of China NSFC 81400487 (LW), and 81570983 (YZ); China Postdoctoral Science Foundation 2015M581405 and $2017 T 100213$ (LW); International Cooperation Project of Science and Technology Jilin Province 20180414030GH (YZ); seed grant (HX) from the University of Maryland Baltimore; and bridge fund (HX) from the University of Maryland School of Dentistry.

\section{Author contributions}

All authors contributed to data analysis, drafting or revising the article, gave final approval of the version to be published, and agree to be accountable for all aspects of the work.

\section{Disclosure}

The authors declare no conflicts of interest in this work.

\section{References}

1. Petersen PE. World Health Organization global policy for improvement of oral health - World Health Assembly 2007. Int Dent J. 2008;58(3):115-121.

2. He J, Li Y, Cao Y, Xue J, Zhou X. The oral microbiome diversity and its relation to human diseases. Folia Microbiol. 2015;60(1):69-80. doi:10.1007/s12223-014-0342-2

3. Murray CJ, Vos T, Lozano R, et al. Disability-adjusted life years (DALYs) for 291 diseases and injuries in 21 regions, 1990-2010: a systematic analysis for the Global Burden of Disease Study 2010. Lancet. 2012;380 (9859):2197-2223. doi:10.1016/S0140-6736(12)61689-4

4. Haapasalo M, Endal U, Zandi H, Coil JM. Eradication of endodontic infection by instrumentation and irrigation solutions. Endod Topics. 2005;10(1):77-102. doi:10.1111/j.1601-1546.2005.00135.x

5. Peters L, Wesselink P, Buijs J, Van Winkelhoff A. Viable bacteria in root dentinal tubules of teeth with apical periodontitis. $J$ Endodont. 2001;27 (2):76-81. doi:10.1097/00004770-200102000-00002
6. Peters L, Wesselink P, Moorer W. Penetration of bacteria in bovine root dentine in vitro. Int Endodon J. 2000;33(1):28-36. doi:10.1046/j.1365-2591.2000.00268.x

7. Hengzhuang W, Wu H, Ciofu O, Song Z, Høiby N. Pharmacokinetics/ pharmacodynamics of colistin and imipenem on mucoid and nonmucoid Pseudomonas aeruginosa biofilms. Antimicrob Agents Ch. 2011;55 (9):4469-4474. doi:10.1128/AAC.00126-11

8. Dai T, Huang YY, Hamblin MR. Photodynamic therapy for localized infections - state of the art. Photodiagn Photodyn. 2009;6(34):170-188. doi:10.1016/j.pdpdt.2009.10.008

9. Hopper C. Photodynamic therapy: a clinical reality in the treatment of cancer. Lancet Oncol. 2000;1(4):212-219. doi:10.1016/S14702045(00)00166-2

10. Hamblin MR, Antimicrobial photodynamic inactivation: a bright new technique to kill resistant microbes. Curr Opin Microbiol. 2016;33:67-73. doi:10.1016/j.mib.2016.06.008

11. Carrera E, Dias H, Corbi S, et al. The application of antimicrobial photodynamic therapy (aPDT) in dentistry: a critical review. Laser Phys. 2016;(26):123001. doi:10.1088/1054-660X/26/12/123001

12. Chrepa V, Kotsakis GA, Pagonis TC, Hargreaves KM. The effect of photodynamic therapy in root canal disinfection: a systematic review. $J$ Endodont. 2014;40(7):891-898. doi:10.1016/j.joen.2014.03.005

13. Trindade AC, De Figueiredo JAP, Steier L, Weber JBB. Photodynamic therapy in endodontics: a literature review. Photomed Laser Surg. 2015;33(3):175-182. doi:10.1089/ pho.2014.3776

14. Javed F, Romanos GE. Does photodynamic therapy enhance standard antibacterial therapy in dentistry? Photomed Laser Surg. 2013;31(11):512-518. doi:10.1089/pho.2012.3329

15. Gursoy H, Ozcakir-Tomruk C, Tanalp J, Yılmaz S. Photodynamic therapy in dentistry: a literature review. Clin Oral Invest. 2013;17 (4):1113-1125. doi:10.1007/s00784-012-0845-7

16. Shrestha A, Kishen A. Antibacterial nanoparticles in endodontics: a review. $J$ Endodon. 2016;42(10):1417-1426. doi:10.1016/ j.joen.2016.05.021

17. Meimandi M, Ardakani MRT, Nejad AE, Yousefnejad P, Saebi K, Tayeed MH. The effect of photodynamic therapy in the treatment of chronic periodontitis: a review of literature. J Lasers Med Sci. 2017;8(Suppl 1):S7. doi:10.15171/jlms.2017.s2

18. Mondal D, Bera S. Porphyrins and phthalocyanines: promising molecules for light-triggered antibacterial nanoparticles. Adv Nat Sci. 2014;5(3):033002. doi:10.1088/2043-6262/5/3/033002

19. Yin R, Agrawal T, Khan U, et al. Antimicrobial photodynamic inactivation in nanomedicine: small light strides against bad bugs. Nanomedicine (London). 2015;10(15):2379-2404. doi:10.2217/ nnm.15.67

20. Huang YY, Sharma SK, Dai T, et al. Can nanotechnology potentiate photodynamic therapy? Nanotechno Rev. 2012;1(2):111-146. doi:10.1515/ntrev-2011-0005

21. Ganoth A, Merimi KC, Peer D. Overcoming multidrug resistance with nanomedicines. Expert Opin Drug Del. 2015;12(2):223-238. doi:10.1517/17425247.2015.960920

22. Pellosi DS, De Jesus PCC, Tedesco AC. Spotlight on the delivery of photosensitizers: different approaches for photodynamic-based therapies. Expert Opin Drug Del. 2017;14(12):1395-1406. doi:10.1080/17425247.2017.1307337

23. Huang YY, Sharma SK, Yin R, Agrawal T, Chiang LY, Hamblin MR. Functionalized fullerenes in photodynamic therapy. $J$ Biomed Nanotechnol. 2014;10(9):1918-1936. doi:10.1166/jbn. 2014.1963

24. Mroz P, Tegos GP, Gali H, Wharton T, Sarna T, Hamblin MR. Photodynamic therapy with fullerenes. Photoch Photobio Sci. 2007;6(11):1139-1149. doi:10.1039/b711141j

25. Hamblin MR. Fullerenes as photosensitizers in photodynamic therapy: pros and cons. Photochem Photobiol Sci. 2018;17(11):15151533. doi:10.1039/C8PP00195B 
26. Aoshima H, Kokubo K, Shirakawa S, Ito M, Yamana S, Oshima T. Antimicrobial activity of fullerenes and their hydroxylated derivatives. Biocontrol Sci. 2009;14(2):69-72. doi:10.4265/bio.14.69

27. Yin R, Wang M, Huang YY, et al. Antimicrobial photodynamic inactivation with decacationic functionalized fullerenes: oxygenindependent photokilling in presence of azide and new mechanistic insights. Free Radical Biol Med. 2015;79:14-27. doi:10.1016/j. freeradbiomed.2014.10.514

28. Grinholc M, Nakonieczna J, Fila G, et al. Antimicrobial photodynamic therapy with fulleropyrrolidine: photoinactivation mechanism of Staphylococcus aureus, in vitro and in vivo studies. Appl Microbiol Biot. 2015;99(9):4031-4043. doi:10.1007/s00253-0156539-8

29. Zhang J, Xu J, Ma H, et al. Designing an amino-fullerene derivative $\mathrm{C} 70-(\mathrm{EDA})_{8}$ to fight super bacteria. ACS Appl Mater Inter. 2019;11(16):14597-14607. doi:10.1021/acsami.9b01483

30. Huang L, Bhayana B, Xuan W, et al. Comparison of two functionalized fullerenes for antimicrobial photodynamic inactivation: potentiation by potassium iodide and photochemical mechanisms. Photoch Photobio B. 2018;186:197-206. doi:10.1016/j.jphotobiol.2018.07.027

31. Zhang Y, Dai T, Wang M, Vecchio D, Chiang LY, Hamblin MR. Potentiation of antimicrobial photodynamic inactivation mediated by a cationic fullerene by added iodide: in vitro and in vivo studies. Nanomedicine. 2015;10(4):603-614. doi:10.2217/nnm.14.131

32. Ballatore MB, Durantini J, Gsponer NS, et al. Photodynamic inactivation of bacteria using novel electrogenerated porphyrin-fullerene $\mathrm{C}_{60}$ polymeric films. Environ Sci Technol. 2015;49(12):74567463. doi:10.1021/acs.est.5b01407

33. Ouyang K, Dai K, Chen H, Huang Q, Gao C, Cai P. Metal-free inactivation of $E$. coli $\mathrm{O} 157$ : $\mathrm{H} 7$ by fullerene $/ \mathrm{C}_{3} \mathrm{~N}_{4}$ hybrid under visible light irradiation. Ecotoxicol Environ Saf. 2017;136:40-45. doi:10.1016/j.ecoenv.2016.10.030

34. Wang Y, Jin Y, Chen W, et al. Construction of nanomaterials with targeting phototherapy properties to inhibit resistant bacteria and biofilm infections. Chem Eng J. 2019;358:74-90. doi:10.1016/j. cej.2018.10.002

35. Calver CF, Schanze KS, Cosa G. Biomimetic light-harvesting antenna based on the self-assembly of conjugated polyelectrolytes embedded within lipid membranes. ACS Nano. 2016;10 (11):10598-10605. doi:10.1021/acsnano.6b07111

36. Jeon S, Haley J, Flikkema J, et al. Linear and nonlinear optical properties of photoresponsive [60] fullerene hybrid triads and tetrads with dual NIR two-photon absorption characteristics. J Phys Chem C. 2013;117(33):17186-17195. doi:10.1021/jp405424q

37. Andrade EB, Martínez A, Free radical scavenger properties of metal-fullerenes: $\mathrm{C}_{60}$ and $\mathrm{C}_{82}$ with $\mathrm{Cu}, \mathrm{Ag}$ and $\mathrm{Au}$ (atoms and tetramers). Comput Theor Chem. 2017;1115:127-135. doi:10.1016/j.comptc.2017.06.015

38. Bai RG, Ninan N, Muthoosamy K, Manickam S. Graphene: a versatile platform for nanotheranostics and tissue engineering. Prog Mater Sci. 2018;(91):24-69. doi:10.1016/j.pmatsci.2017.08.004

39. Ristic BZ, Milenkovic MM, Dakic IR, et al. Photodynamic antibacterial effect of graphene quantum dots. Biomaterials. 2014;35 (15):4428-4435. doi:10.1016/j.biomaterials.2014.02.014

40. Xie X, Ma C, Liu X, et al. Synergistic bacteria killing through photodynamic and physical actions of graphene oxide/Ag/collagen coating. ACS Appl Mater Inter. 2017;9(31):26417-26428. doi:10.1021/acsami.7b06702

41. Kuo WS, Chen HH, Chen SY, et al. Graphene quantum dots with nitrogen-doped content dependence for highly efficient dual-modality photodynamic antimicrobial therapy and bioimaging. Biomaterials. 2017;120:185-194. doi:10.1016/j.biomaterials.2016.12.022

42. Santos CI, Gonçalves G, Cicuéndez M, et al. Biocompatible hybrids based on nanographene oxide covalently linked to glycolporphyrins: synthesis, characterization and biological evaluation. Carbon. 2018;135:202-214. doi:10.1016/j.carbon.2018.04.040
43. Xu X, Ho W, Zhang X, Bertrand N, Farokhzad O. Cancer nanomedicine: from targeted delivery to combination therapy. Trends Mol Med. 2015;21(4):223-232. doi:10.1016/j.molmed.2015.01.001

44. Tian B, Wang C, Zhang S, Feng L, Liu Z. Photothermally enhanced photodynamic therapy delivered by nano-graphene oxide. ACS Nano. 2011;5(9):7000-7009. doi:10.1021/nn201560b

45. Sah U, Sharma K, Chaudhri N, Sankar M, Gopinath P. Antimicrobial photodynamic therapy: single-walled carbon nanotube (SWCNT)-Porphyrin conjugate for visible light mediated inactivation of Staphylococcus aureus. Colloids Surf B. 2018;162:108117. doi:10.1016/j.colsurfb.2017.11.046

46. Banerjee I, Mondal D, Martin J, Kane RS. Photoactivated antimicrobial activity of carbon nanotube-porphyrin conjugates. Langmuir. 2010;26(22):17369-17374. doi:10.1021/la103298e

47. Xiao H, Zhu B, Wang D, et al. Photodynamic effects of chlorin e6 attached to single wall carbon nanotubes through noncovalent interactions. Carbon. 2012;50(4):1681-1689. doi:10.1016/j. carbon.2011.12.013

48. Anju VT, Paramanantham A, Sharan A, et al. Antimicrobial photodynamic activity of rose bengal conjugated multi walled carbon nanotubes against planktonic cells and biofilm of Escherichia coli. Photodiagn Photodyn. 2018;24:300-310. doi:10.1016/j.pdpdt.2018.10.013

49. Sáfar GA, Gontijo RN, Fantini C, et al. Enhanced oxygen singlet production by hybrid system of porphyrin and enriched $(6,5)$ single-walled carbon nanotubes for photodynamic therapy. $J$ Phys Chem C. 2015;119(8):4344-4350. doi:10.1021/jp5111289

50. Zhu Z, Tang Z, Phillips JA, Yang R, Wang H, Tan W. Regulation of singlet oxygen generation using single-walled carbon nanotubes. J Am Chem Soc. 2008;130(33):10856-10857. doi:10.1021/ ja802913f

51. Sarwar S, Chakraborti S, Bera S, Sheikh IA, Hoque KM, Chakrabarti P. The antimicrobial activity of $\mathrm{ZnO}$ nanoparticles against Vibrio cholerae: variation in response depends on biotype. Nanomedicine. 2016;12(6):1499-1509. doi:10.1016/j. nano.2016.02.006

52. Colmenares JC, Luque R. Heterogeneous photocatalytic nanomaterials: prospects and challenges in selective transformations of biomass-derived compounds. Chem Soc Rev. 2014;43(3):765-778. doi:10.1039/c3cs60262a

53. Podporska-Carroll J, Myles A, Quilty B, et al. Antibacterial properties of F-doped $\mathrm{ZnO}$ visible light photocatalyst. J Hazard Mater. 2017;324:39-47. doi:10.1016/j.jhazmat.2015.12.038

54. Sethi D, Sakthivel R. $\mathrm{ZnO} / \mathrm{TiO}_{2}$ composites for photocatalytic inactivation of Escherichia coli. Photoch Photobio B. 2017;168:117-123. doi:10.1016/j.jphotobiol.2017.02.005

55. Reddy KR, Karthik K, Prasad SB, Soni SK, Jeong HM, Raghu AV. Enhanced photocatalytic activity of nanostructured titanium dioxide/polyaniline hybrid photocatalysts. Polyhedron. 2016;120:169174. doi:10.1016/j.poly.2016.08.029

56. Suketa N, Sawase T, Kitaura H, et al. An antibacterial surface on dental implants, based on the photocatalytic bactericidal effect. Clin Implant Dent R. 2005;7(2):105-111. doi:10.1111/j.1708-8208.2005.tb00053.x

57. Lilja M, Forsgren J, Welch K, Åstrand M, Engqvist H, Strømme M. Photocatalytic and antimicrobial properties of surgical implant coatings of titanium dioxide deposited though cathodic arc evaporation. Biotechnol Lett. 2012;34(12):2299-2305. doi:10.1007/s10529-0121040-2

58. Huang YY, Choi H, Kushida Y, Bhayana B, Wang Y, Hamblin MR. Broad-spectrum antimicrobial effects of photocatalysis using titanium dioxide nanoparticles are strongly potentiated by addition of potassium iodide. Antimicrob Agents Ch. 2016;60(9):5445-5453. doi:10.1128/AAC.00980-16

59. Gao L, Giglio KM, Nelson JL, Sondermann H, Travis AJ. Ferromagnetic nanoparticles with peroxidase-like activity enhance the cleavage of biological macromolecules for biofilm elimination. Nanoscale. 2014;6(5):2588-2593. doi:10.1039/c3nr05422e 
60. Tassa C, Shaw SY, Weissleder R. Dextran-coated iron oxide nanoparticles: a versatile platform for targeted molecular imaging, molecular diagnostics, and therapy. Accounts Chem Res. 2011;44 (10):842-852. doi:10.1021/ar200084x

61. Choi KH, Lee HJ, Park BJ, et al. Photosensitizer and vancomycinconjugated novel multifunctional magnetic particles as photoinactivation agents for selective killing of pathogenic bacteria. Chem Commun. 2012;48(38):4591-4593. doi:10.1039/c2cc17766h

62. Pan WY, Huang CC, Lin TT, et al. Synergistic antibacterial effects of localized heat and oxidative stress caused by hydroxyl radicals mediated by graphene/iron oxide-based nanocomposites. Nanomedicine. 2016;12(2):431-438. doi:10.1016/j. nano.2015.11.014

63. Cui S, Yin D, Chen Y, et al. In vivo targeted deep-tissue photodynamic therapy based on near-infrared light triggered upconversion nanoconstruct. ACS Nano. 2012;7(1):676-688. doi:10.1021/ nn304872n

64. Haase M, Schäfer H. Upconverting nanoparticles. Angew Chem Int Edit. 2011;50(26):5808-5829. doi:10.1002/anie.201005159

65. Zhang Y, Huang P, Wang D, et al. Near-infrared-triggered antibacterial and antifungal photodynamic therapy based on lanthanidedoped upconversion nanoparticles. Nanoscale. 2018;10(3):1548515495. doi:10.1039/c8nr01967c

66. Xu F, Hu M, Liu C, Choi SK. Yolk-structured multifunctional upconversion nanoparticles for synergistic photodynamic-sonodynamic antibacterial resistance therapy. Biometer Sci. 2017;5 (4):678-685. doi:10.1039/C7BM00030H

67. Grüner MC, Arai MS, Carreira M, Inada N, Camargo ASS. Functionalizing the mesoporous silica shell of upconversion nanoparticles to enhance bacterial targeting and killing via photosensitizer-induced antimicrobial photodynamic therapy. ACS Appl Bio Mater. 2018;1(4):1028-1036. doi:10.1021/acsabm.8b00224

68. Yin M, Li Z, Ju E, et al. Multifunctional upconverting nanoparticles for near-infrared triggered and synergistic antibacterial resistance therapy. Chem Commun. 2014;50(72):10488-10490. doi:10.1039/ C4CC04584J

69. Amini SM, Kharrazi S, Hadizadeh M, Fateh M, Saber R. Effect of gold nanoparticles on photodynamic efficiency of 5-aminolevolenic acid photosensitiser in epidermal carcinoma cell line: an in vitro study. IET Nanobiotechnol. 2013;7(4):151-156. doi:10.1049/ietnbt.2013.0021

70. Darabpour E, Kashef N, Amini SM, Kharrazi S, Djavid GE. Fast and effective photodynamic inactivation of 4-day-old biofilm of methicillin-resistant Staphylococcus aureus using methylene blueconjugated gold nanoparticles. J Drug Deliv Sci Tec. 2017;37:134140. doi:10.1016/j.jddst.2016.12.007

71. Maliszewska I, Leśniewska A, Olesiak-Bańska J, Matczyszyn K, Samoć M. Biogenic gold nanoparticles enhance methylene blueinduced phototoxic effect on Staphylococcus epidermidis. J Nanopart Res. 2014;16(6):2457. doi:10.1007/s11051-014-2457-4

72. Turcheniuk K, Turcheniuk V, Hage $\mathrm{CH}$, et al. Highly effective photodynamic inactivation of $E$. coli using gold nanorods $/ \mathrm{SiO}_{2}$ core-shell nanostructures with embedded verteporfin. Chem Commun. 2015;51(91):16365-16368. doi:10.1039/C5CC06738C

73. Planas O, Bresolí-Obach R, Nos J, et al. Synthesis, photophysical characterization, and photoinduced antibacterial activity of methylene blue-loaded amino-and mannose-targeted mesoporous silica nanoparticles. Molecules. 2015;20(4):6284-6298. doi:10.3390/ molecules20046284

74. Brevet D, Gary-Bobo M, Raehm L, et al.Mannose-targeted mesoporous silica nanoparticles for photodynamic therapy. Chem Commun. 2009;(12):1475-1477. doi:10.1039/b900427k

75. Wysocka-Król K, Olsztyńska-Janus S, Plesch G, Plecenik A, Podbielska H, Bauer J. Nano-silver modified silica particles in antibacterial photodynamic therapy. Appl Surf Sci. 2018;461:260268. doi:10.1016/j.apsusc.2018.05.014
76. Lin J, Li J, Gopal A, et al. Synthesis of photo-excited Chlorin e6 conjugated silica nanoparticles for enhanced anti-bacterial efficiency to overcome methicillin-resistant Staphylococcus aureus. Chem Commun. 2019;55(18):2656-2659. doi:10.1039/C9CC00166B

77. Sadasivam M, Avci P, Gupta GK, et al. Self-assembled liposomal nanoparticles in photodynamic therapy. Eur J Nanomed. 2013;5 (3):115-129. doi:10.1515/ejnm-2013-0010

78. Mesquita MQ, Dias CJ, Neves M PMS, Almeida A, Faustino MAF. Revisiting current photoactive materials for antimicrobial photodynamic therapy. Molecules. 2018;23(10):2424. doi:10.3390/molecules23102424

79. Yang K, Gitter B, Rüger R, et al. Antimicrobial peptide-modified liposomes for bacteria targeted delivery of temoporfin in photodynamic antimicrobial chemotherapy. Photoch Photobio Sci. 2011;10 (10):1593-1601. doi:10.1039/c1pp05100h

80. Jia Y, Joly H, Omri A. Characterization of the interaction between liposomal formulations and Pseudomonas aeruginosa. J Liposome Res. 2010;20(2):134-146. doi:10.3109/08982100903218892

81. Jin CS, Zheng G. Liposomal nanostructures for photosensitizer delivery. Laser Surg Med. 2011;43(7):734-748. doi:10.1002/ $1 \mathrm{sm} .21101$

82. Nitzan Y, Dror R, Ladan H, Malik Z, Kimel S, Gottfried V. Structure-activity relationship of porphines for photoinactivation of bacteria. Photochem Photobiol. 1995;62(2):342-347. doi:10.1111/j.1751-1097.1995.tb05279.x

83. Yang YT, Chien HF, Chang PH, et al. Photodynamic inactivation of chlorin e6-loaded CTAB-liposomes against Candida albicans. Laser Surg Med. 2013;45(3):175-185. doi:10.1002/lsm.22124

84. Park H, Lee J, Jeong S, et al. Lipase-sensitive transfersomes based on photosensitizer/polymerizable lipid conjugate for selective antimicrobial photodynamic therapy of acne. Adv Healthc Mater. 2016;5(24):3139-3147. doi:10.1002/adhm.201600815

85. Deng X, Liang Y, Peng X, et al. A facile strategy to generate polymeric nanoparticles for synergistic chemo-photodynamic therapy. Chem Commun. 2015;51(20):4271-4274. doi:10.1039/C4CC10226F

86. Conte C, Maiolino S, Pellosi DS, Miro A, Ungaro F, Quaglia F. Polymeric nanoparticles for cancer photodynamic therapy. In: Sortino S, editor. Light-responsive Nanostructured Systems for Applications in Nanomedicine. Springer International Publishing Switzerland; 2016:61-112.

87. Xiao F, Cao B, Wang C, et al. Pathogen-specific polymeric antimicrobials with significant membrane disruption and enhanced photodynamic damage to inhibit highly opportunistic bacteria. ACS Nano. 2019;13(2):1511-1525. doi:10.1021/acsnano.8b07251

88. Darabpour E, Kashef N, Mashayekhan S. Chitosan nanoparticles enhance the efficiency of methylene blue-mediated antimicrobial photodynamic inactivation of bacterial biofilms: an in vitro study. Photodiagn Photodyn. 2016;14:211-217. doi:10.1016/j.pdpdt.2016. 04.009

89. Pourhajibagher M, Rostami Rad M, Bahador A. Monitoring of virulence factors and metabolic activity in Aggregatibacter actinomycetemcomitans cells surviving antimicrobial photodynamic therapy via nano-chitosan encapsulated indocyanine green. Front Phys. 2018;6:124. doi:10.3389/fphy.2018.00124

90. Shrestha A, Kishen A. Polycationic chitosan-conjugated photosensitizer for antibacterial photodynamic therapy. Photochem Photobiol. 2012;88 (3):577-583. doi:10.1111/j.1751-1097.2011.01026.x

91. Chen CP, Chen CT, Tsai T. Chitosan nanoparticles for antimicrobial photodynamic inactivation: characterization and in vitro investigation. Photochem Photobiol. 2012;88(3):570-576. doi:10.1111/ j.1751-1097.2012.01101.x

92. Choi SS, Lee HK, Chae HS. Synergistic in vitro photodynamic antimicrobial activity of methylene blue and chitosan against Helicobacter pylori 26695. Photodiagn Photodyn. 2014;11 (4):526-532. doi:10.1016/j.pdpdt.2014.08.005 
93. Carpenter BL, Feese E, Sadeghifar H, Argyropoulos DS, Ghiladi RA. Porphyrin-cellulose nanocrystals: a photobactericidal material that exhibits broad spectrum antimicrobial activity. Photochem Photobiol. 2012;88(3):527-536. doi:10.1111/j.1751-1097.2012.01117.x

94. Pagonis TC, Chen J, Fontana CR, et al. Nanoparticle-based endodontic antimicrobial photodynamic therapy. J Endodon. 2010;36 (2):322-328. doi:10.1016/j.joen.2009.10.011

95. González-Delgado JA, Castro PM, Machado A, et al. Hydrogels containing porphyrin-loaded nanoparticles for topical photodynamic applications. Int $J$ Pharm. 2016;510(1):221-231. doi:10.1016/j.ijpharm.2016.06.037

96. de Freitas L, Calixto G, Chorilli M, et al. Polymeric nanoparticlebased photodynamic therapy for chronic periodontitis in vivo. Int $J$ Mol Sci. 2016;17(5):769. doi:10.3390/ijms17050769

97. Liu S, Qiao S, Li L, et al. Surface charge-conversion polymeric nanoparticles for photodynamic treatment of urinary tract bacterial infections. Nanotechnology. 2015;26(49):495602. doi:10.1088/ 0957-4484/26/49/495602

98. Felgenträger A, Maisch T, Späth A, et al. Singlet oxygen generation in porphyrin-doped polymeric surface coating enables antimicrobial effects on Staphylococcus aureus. Phys Chem Chem Phys. 2014;16 (38):20598-20607. doi:10.1039/c4cp02439g

99. Ma BC, Ghasimi S, Landfester K, et al. Enhanced visible light promoted antibacterial efficiency of conjugated microporous polymer nanoparticles via molecular doping. J Mater Chem B. 2016;4 (30):5112-5118. doi:10.1039/C6TB00943C

100. Stanley S, Scholle F, Zhu J, et al. Photosensitizer-embedded polyacrylonitrile nanofibers as antimicrobial non-woven textile. Nanomaterials. 2016;6(4):77. doi:10.3390/nano6040077

101. de Avila ED, Lima BP, Sekiya T, et al. Effect of UV-photofunctionalization on oral bacterial attachment and biofilm formation to titanium implant material. Biomaterials. 2015;67:84-92. doi:10.1016/j.biomaterials.2015.07.030

102. D'Orazio J, Jarrett S, Amaro-Ortiz A, Scott T. UV radiation and the skin. Int J Mol Sci. 2013;14(6):12222-12248. doi:10.3390/ijms 140612222

103. Shi CH, Zhu NW, Cao YL, Wu PX. Biosynthesis of gold nanoparticles assisted by the intracellular protein extract of Pycnoporus sanguineus and its catalysis in degradation of 4-nitroaniline. Nanoscale Res Lett. 2015;10(1):147. doi:10.1186/s11671-015-0856-9

104. Tim M. Strategies to optimize photosensitizers for photodynamic inactivation of bacteria. $J$ Photoch Photobio B. 2015;150:2-10. doi:10.1016/j.jphotobiol.2015.05.010

105. Kishen A. Advanced Therapeutic Options to Disinfect Root Canals. In: Chávez de Paz LE, Sedgley CM, Kishen A, editors. The Root Canal Biofilm. Springer-Verlag Berlin Heidelberg; 2015:334-335.

106. Gatoo MA, Naseem S, Arfat MY, Mahmood Dar A, Qasim K, Zubair S. Physicochemical properties of nanomaterials: implication in associated toxic manifestations. Biomed Res Int. 2014;2014:1-8. doi: $10.1155 / 2014 / 498420$

107. Chi M, Qi M, Lan A, et al. Novel bioactive and therapeutic dental polymeric materials to inhibit periodontal pathogens and biofilms. Int J Mol Sci. 2019;20(2):278. doi:10.3390/ijms200 20278

108. Beytollahi L, Pourhajibagher M, Chiniforush N, et al. The efficacy of photodynamic and photothermal therapy on biofilm formation of Streptococcus mutans: an in vitro study. Photodiagn Photodyn. 2017;17:56-60. doi:10.1016/j.pdpdt.2016.10.006

109. Araújo N, Fontana CR, Bagnato V, Gerbi M. Photodynamic antimicrobial therapy of curcumin in biofilms and carious dentine. Laser Med Sci. 2014;29(2):629-635. doi:10.1007/s10103-0131369-3

110. Misba L, Kulshrestha S, Khan AU. Antibiofilm action of a toluidine blue O-silver nanoparticle conjugate on Streptococcus mutans: a mechanism of type I photodynamic therapy. Biofouling. 2016;32 (3):313-328. doi:10.1080/08927014.2016.1141899
111. Parker S. The use of diffuse laser photonic energy and indocyanine green photosensitiser as an adjunct to periodontal therapy. Brit Dent J. 2013;215(4):167. doi:10.1038/sj.bdj.2013.790

112. Gholibegloo E, Karbasi A, Pourhajibagher M, et al. Carnosine-graphene oxide conjugates decorated with hydroxyapatite as promising nanocarrier for ICG loading with enhanced antibacterial effects in photodynamic therapy against Streptococcus mutans. $J$ Photoch Photobio $B$. 2018;181:14-22. doi:10.1016/j.jphotobiol.2018.02.004

113. Siqueira JF Jr. Endodontic infections: concepts, paradigms, and perspectives. Oral Surg Oral Med O. 2002;94(3):281-293. doi:10.1067/moe.2002.126163

114. Stojanović N, Krunić J, Popović B, Stojičić S, Živković S. Prevalence of Enterococcus faecalis and Porphyromonas gingivalis in infected root canals and their susceptibility to endodontic treatment procedures: a molecular study. Srp Ark Celok Lek. 2014;142 (9-10):535-541. doi:10.2298/SARH1410535S

115. Komiyama EY, Lepesqueur LSS, Yassuda CG, et al. Enterococcus species in the oral cavity: prevalence, virulence factors and antimicrobial susceptibility. PLoS One. 2016;11(9):e0163001. doi:10.1371/journal.pone. 0163001

116. Slutzky-Goldberg I, Maree M, Liberman R, Heling I. Effect of sodium hypochlorite on dentin microhardness. $J$ Endodon. 2004;30:880-882. doi:10.1097/01.DON.0000128748.05148.1E

117. Ari $\mathrm{H}$, Yaşar E, Bellí $\mathrm{S}$. Effects of $\mathrm{NaOCl}$ on bond strengths of resin cements to root canal dentin. J Endodon. 2003;29(4):248251. doi:10.1097/00004770-200304000-00004

118. Shrestha A, Kishen A. Antibacterial efficacy of photosensitizer functionalized biopolymeric nanoparticles in the presence of tissue inhibitors in root canal. $J$ Endodon. 2014;40(4):566-570. doi:10.1016/j.joen.2013.09.013

119. Shrestha A, Kishen A. Antibiofilm efficacy of photosensitizerfunctionalized bioactive nanoparticles on multispecies biofilm. $J$ Endod. 2014;40(10):1604-1610. doi:10.1016/j.joen.2014. 03.009

120. Shrestha A, Hamblin MR, Kishen A. Photoactivated rose bengal functionalized chitosan nanoparticles produce antibacterial/biofilm activity and stabilize dentin-collagen. Nanomedicine. 2014;10 (3):491-501. doi:10.1016/j.nano.2013.10.010

121. Shrestha A, Cordova M, Kishen A. Photoactivated polycationic bioactive chitosan nanoparticles inactivate bacterial endotoxins. $J$ Endodon. 2015;41(5):686-691. doi:10.1016/j.joen.2014.12.007

122. Akbari T, Pourhajibagher M, Hosseini F, et al. The effect of indocyanine green loaded on a novel nano-graphene oxide for high performance of photodynamic therapy against Enterococcus faecalis. Photodiagn Photodyn. 2017;20:148-153. doi:10.1016/j. pdpdt.2017.08.017

123. Afkhami F, Akbari S, Chiniforush N. Entrococcus faecalis elimination in root canals using silver nanoparticles, photodynamic therapy, diode laser, or laser-activated nanoparticles: an in vitro study. J Endodon. 2017;43(2):279-282. doi:10.1016/j.joen.2016. 08.029

124. Golmohamadpour A, Bahramian B, Khoobi M, Pourhajibagher M, Barikani HR, Bahador A. Antimicrobial photodynamic therapy assessment of three indocyanine green-loaded metal-organic frameworks against Enterococcus faecalis. Photodiagn Photocyn. 2018;23:331-338. doi:10.1016/j.pdpdt.2018.08.004

125. Klepac-Ceraj V, Patel N, Song X, et al. Photodynamic effects of methylene blue-loaded polymeric nanoparticles on dental plaque bacteria. Laser Surg Med. 2011;43(7):600-606. doi:10.1002/ $1 \mathrm{sm} .21069$

126. Nagahara A, Mitani A, Fukuda M, et al. Antimicrobial photodynamic therapy using a diode laser with a potential new photosensitizer, indocyanine green-loaded nanospheres, may be effective for the clearance of Porphyromonas gingivalis. J Periodontal Res. 2013;48(5):591-599. doi:10.1111/jre.12042 
127. Sasaki Y, Hayashi J, Fujimura T, et al. New irradiation method with indocyanine green-loaded nanospheres for inactivating periodontal pathogens. Int J Mol Sci. 2017;(18):154. doi:10.3390/ ijms 18010154

128. Sun X, Wang L, Lynch C, et al. Nanoparticles having amphiphilic silane containing Chlorin e6 with strong anti-biofilm activity against periodontitis-related pathogens. J Dent. 2019;81:70-84. doi:10.1016/j.jdent.2018.12.011

129. Socransky SS, Haffajee AD, Cugini MA, Smith C, Kent RL. Microbial complexes in subgingival plaque. J Clin Periodontol. 1998;25(2):134-144. doi:10.1111/j.1600-051X.1998.tb02419.x

130. Mombelli A, Lang NP. The diagnosis and treatment of peri-implantitis. Periodontol 2000. 1998;17(1):63-76. doi:10.1111/j.16000757.1998.tb00124.x

131. Besinis A, Hadi SD, Le H, Tredwin C, Handy R. Antibacterial activity and biofilm inhibition by surface modified titanium alloy medical implants following application of silver, titanium dioxide and hydroxyapatite nanocoatings. Nanotoxicology. 2017;11(3):327338. doi:10.1080/17435390.2017.1299890

132. Coronado-Castellote L, Jiménez-Soriano Y. Clinical and microbiological diagnosis of oral candidiasis. J Clin Exp Dent. 2013;5(5): e279-e286. doi:10.4317/jced.51242

133. Colomba C, Trizzino M, Imburgia C, Madonia S, Siracusa L, Giammanco GM. Candida glabrata meningitis and endocarditis: a late severe complication of candidemia. Int $J$ Infect Dis. 2014;29:174-175. doi:10.1016/j.ijid.2014.04.032

134. Williams D, Lewis M. Pathogenesis and treatment of oral candidosis. J Oral Microbiol. 2011;3(1):5771. doi:10.3402/jom. v3i0.5771
135. Mthethwa T, Nyokong T. Photoinactivation of Candida albicans and Escherichia coli using aluminium phthalocyanine on gold nanoparticles. Photoch Photobio Sci. 2015;14:1346-1356. doi:10.1039/C4PP00315B

136. Sherwani MA, Tufail S, Khan AA, Owais M. Gold nanoparticlephotosensitizer conjugate based photodynamic inactivation of biofilm producing cells: potential for treatment of $C$. albicans infection in BALB/c mice. PLoS One. 2015;10(7):e0131684. doi:10.1371/ journal.pone. 0131684

137. Teerakapong A, Damrongrungruang T, Sattayut S, Morales NP, Sangpanya A, Tanapoomchai M. Fungicidal effect of combined nano $\mathrm{TiO}_{2}$ with erythrosine for mediated photodynamic therapy on Candida albicans: an in vitro study. Laser Dent Sci. 2017;1(24):101-106. doi:10.1007/s41547-017-0014-z

138. Pastar I, Nusbaum AG, Gil J, et al. Interactions of methicillin resistant Staphylococcus aureus USA300 and Pseudomonas aeruginosa in polymicrobial wound infection. PLoS One. 2013;8(2): e56846. doi:10.1371/journal.pone.0056846

139. $\mathrm{Xu} \mathrm{Z}$, Wang $\mathrm{X}$, Liu $\mathrm{X}$, et al. Tannic acid/ $/ \mathrm{Fe}^{3+} / \mathrm{Ag}$ nanofilm exhibiting superior photodynamic and physical antibacterial activity. ACS Appl Mater Inter. 2017;9(45):39657-39671. doi:10.1021/acsami.7b10818

140. Li S, Cui S, Yin D, et al. Dual antibacterial activities of a chitosanmodified upconversion photodynamic therapy system against drugresistant bacteria in deep tissue. Nanoscale. 2017;9(11):3912-3924. doi:10.1039/c6nr07188k

141. Dong K, Ju E, Gao N, Wang Z, Ren J, Qu X. Synergistic eradication of antibiotic-resistant bacteria based biofilms in vivo using a NIR-sensitive nanoplatform. Chem Commun. 2016;52(30):53125315. doi:10.1039/C6CC00774K
International Journal of Nanomedicine

\section{Publish your work in this journal}

The International Journal of Nanomedicine is an international, peerreviewed journal focusing on the application of nanotechnology in diagnostics, therapeutics, and drug delivery systems throughout the biomedical field. This journal is indexed on PubMed Central, MedLine, CAS, SciSearch ${ }^{\mathbb{}}$, Current Contents ${ }^{\mathbb{R}} /$ Clinical Medicine,
Journal Citation Reports/Science Edition, EMBase, Scopus and the Elsevier Bibliographic databases. The manuscript management system is completely online and includes a very quick and fair peer-review system, which is all easy to use. Visit http://www.dovepress.com/ testimonials.php to read real quotes from published authors. 